Discussion Paper No. 732

\title{
FAT DEBTORS: \\ TIME DISCOUNTING, ITS ANOMALIES, AND BODY MASS INDEX
}

\author{
Shinsuke Ikeda \\ Kang Myong-II \\ Fumio Ohtake
}

March 2009

The Institute of Social and Economic Research Osaka University

6-1 Mihogaoka, Ibaraki, Osaka 567-0047, Japan 


\title{
Fat Debtors: \\ Time Discounting, Its Anomalies, and Body Mass Index ${ }^{1}$
}

\author{
Ikeda, Shinsuke, ${ }^{2}$ Myong-Il, Kang, ${ }^{3}$ and Fumio Ohtake ${ }^{4}$ \\ ISER, Osaka University
}

March 6, 2009

\footnotetext{
${ }^{1}$ Our special thanks go to I. Shimomura and T. Hunahashi (Graduate School of Medicine, Osaka University) for helpful comments from the viewpoint of medical science. We are also grateful to Y. Fukuta, D. Kawaguchi, K. Hirata, C.Y. Horioka and participants at the 2008 meeting of the Association of Behavioral Economics and Finance and the faculty seminars of Hitotsubashi and Osaka Universities for beneficial discussions. We appreciate financial supports for Ikeda from Grantsin-Aid for Scientific Research (C No. 1553021) from the Japan Society for the Promotion of Science (JSPS) and the COE and the Global COE Programs from the Ministry of Education, Culture, Sports, and Science and Technology.

${ }^{2}$ Corresponding author: S. Ikeda, The Institute of Social and Economic Research, Osaka University, 6-1 Mihogaoka, Ibaraki, Osaka 567-0047, Japan. Telephone: 81-6-6879-8568. E-mail: <ikeda@iser.osaka-u.ac.jp>.

${ }^{3}$ M. Kang, The Institute of Social and Economic Research, Osaka University, 6-1 Mihogaoka, Ibaraki, Osaka 567-0047, Japan. Telephone: 81-6-6879-8568. Email: <myong_il_econ@yahoo.co.jp>.

${ }^{4}$ F. Ohtake, The Institute of Social and Economic Research, Osaka University, 6-1 Mihogaoka, Ibaraki, Osaka 567-0047, Japan. Telephone: 81-6-6879-8572. Email: <ohtake@iser.osaka-u.ac.jp>.
} 


\begin{abstract}
In view of the finding that debtors are likely to be more obese than nondebtors, we investigate whether interpersonal differences in body mass are, as in the case of debt behavior, related to those in time discounting and time discounting anomalies. The effects of time discounting on body mass index (BMI) and the probabilities of being obese, severely obese, and underweight are detected by incorporating three properties of intertemporal preferences: (i) impatience, measured by the level of the respondents' discount rate; (ii) hyperbolic discounting, where discount rates for the discounting of immediate future payoffs are higher than those of distant future payoffs; and (iii) the sign effect, wherein future negative payoffs are discounted at a lower rate than are future positive payoffs. We also find that body mass is non-monotonically correlated with age, income, and working hours. As a policy implication, body mass can potentially be controlled by changing the intertemporal structure of medical care costs.
\end{abstract}

Keywords: BMI, obesity, underweight, time preference, discount rate, hyperbolic discounting, procrastination, the sign effect.

JEL classification: I10; Z00. 


\section{Introduction}

As in the case of other advanced countries, the number of obese individuals in Japan has been increasing, and this has been accompanied by associated increases in social costs including health care costs. However, one distinct feature in Japan is that in addition to obesity, underweight, too, is widely observed. According to the National Survey of Health and Nutrition 2004 (hereafter, NSHN04), conducted by the Ministry of Health, Labour and Welfare of Japan, the prevalence rate of obesity in Japanese adults amounts to nearly $30 \%$ for males and $20 \%$ for females. On the other hand, nearly $5 \%$ of male adults and $10 \%$ of female adults are underweight. In particular, the prevalence rate of underweight among females in their 20s exceeds $20 \%$. Thus, it is important to examine the causes of these wide interpersonal differences in body mass.

According to economic theory, optimal caloric intake is determined by the condition that the present utility derived from marginal caloric intake netted of its costs be equal to the discounted future marginal disutility derived from being overweight (e.g., Cutler et al., 2003). The resulting body mass would depend on consumers' preferences regarding time discounting and risk aversion, lifetime income, and the costs of caloric intake in terms of time and money. Among other factors, people's time preferences or discount rates have been focused on as a key determinant of body mass and has been regarded as important, especially in explaining the interpersonal differences in body mass (e.g., Komlos et al., 2004; Smith et al., 2005; and Borghans and Golsteyn, 2006). ${ }^{1}$ Those less patient, namely, those with higher time preferences, are likely to discount more intensively the future disutility of obesity, and would hence be more likely to be obese than those more patient, namely, those with lower time preferences.

As suggested by the title of the paper, there is consistent evidence suggesting that debtors are likely to be more obese than non-debtors. By using data from a Japanese survey conducted in 2005 (the Japan Household Survey on Consumer Preferences and Satisfaction 2005, which is explained later), Table 1 compares the body mass of debtors and non-debtors while excluding housing loans from the debts. Body mass index (BMI), the standard measure of body mass, is defined as weight in kilograms divided by height in meters squared $\left(\mathrm{kg} / \mathrm{m}^{2}\right)$. Both for the male and female samples, the table indicates that debtors are significantly more obese than non-debtors (the definitions

\footnotetext{
${ }^{1}$ The cost factor is important, especially in explaining the dynamics of peoples' body mass. Cutler at al. (2003) and Chou et al. (2004) find that technological progress and the resulting decrease in calorie prices could explain the recent rapid increases in the obesity prevalence rate in the U.S.
} 
of obesity, etc., will be provided later). Because time discounting plays a key role in determining debt holdings as a result of intertemporal resource allocation, the significant correlation between body mass and debt holdings suggests that time discounting may actually affect body mass formation.

Insert Table 1:

Debt holdings and body mass

By using Japanese survey data, this paper aims to examine the determinants of interpersonal differences in body mass, especially focusing on the empirical validity of the hypothesis that body mass is related to time discounting. The novelty of our study lies in the fact that it investigates the effects of not only impatience, measured by the level of respondents' discount rate, but also the effects of two time discounting anomalies that have been empirically reported and predicted to affect debt holding behavior. ${ }^{2}$ One time discounting anomaly is hyperbolic discounting or the immediacy effect, under which a person discounts his/her immediate futures more intensively than his/her distant futures (e.g., Thaler, 1981 and Benzion et al., 1989). Hyperbolic discounting causes consumers to procrastinate saving and thereby hold excessive debts (e.g., Laibson, 1997, 1998). The other time discounting anomaly is the sign effect, under which a person discounts positive payoffs more intensively than negative payoffs. This anomaly makes consumers reluctant to pay interest in the future, thereby leading to "borrowing aversion" behavior (Loewenstein and Prelec, 1992).

In view of the strong correlation between debt holdings and body mass, as shown in Table 1, it would be plausible to apply the same logic of the debt theory to body mass determination and hence to assume that the two time discounting anomalies affect body mass. As Cutler et al. (2003) predict, hyperbolic discounting leads people to procrastinate controlling their immediate appetite and to instead eat excessive cheap, fatty foods. The sign effect leads people to try and control caloric intake in order to avoid bearing the future psychological and/or monetary costs of obesity, such as the hardships of dieting, costs of having to buy new larger sized clothes, and medical services. We hypothesize that, as in the case of debt holdings, body mass is related positively to the degrees of impatience and hyperbolic discounting, and negatively to the sign effect. Our main interest involves investigating the empirical validity of this hypothesis.

\footnotetext{
${ }^{2}$ For a comprehensive survey on time discounting anomalies, see, for example, Frederick, et al. (2002).
} 
The relationships between body mass and time preference have been empirically examined in the literature. By using international cross-sectional macro data, Komlos et al. (2004) find that the prevalence rate of obesity in the Western advanced countries is negatively correlated with the national savings rate as a reverse proxy for national time preference. Using cross-sectional data from a National Longitudinal Survey of Youth (NLSY) conducted in the U.S., Smith et al. (2005) report a significant negative correlation between BMI and savings, which they used as a reverse proxy for time preference. From Dutch survey data, Borghans and Golsteyn (2006) construct a variety of proxies for time discounting to show that the respondents' BMI is positively correlated with the time preference proxies. However, the proxies for time preference used in these studies are not very refined. For example, savings may well depend on variables other than time preference, such as income, age, and especially the magnitudes of the time discounting anomalies. For savings to be an accurate proxy for time preference, the effects of the other determinants should be controlled for.

To eliminate this problem, we construct two kinds of time preference data. First, by administering questionnaires on intertemporal monetary choices under alternative conditions, we obtain individuals' discount rates. This enables us (i) to construct time preference data as a measure of impatience by computing the normalized mean of the elicited discount rates, and (ii) to construct indicator variables for hyperbolic discounting and the sign effect. Second, we construct a time preference proxy from the debt holding data. This proxy is estimated to be the residual after regressing debt holdings on the degree of procrastination, the sign effect, income, and the determinants other than time preference.

After controlling for demographic and economic factors, the main results reveal that the time discounting anomalies as well as impatience jointly predict respondents' body mass index and their probabilities of being obese and underweight; moreover, the significance levels are higher for the female sample than for the male sample.

Further, body mass is non-monotonically correlated with age, per capita household income, and working hours. For example, BMI is found to be quadratic in per capita income with a positive coefficient on the income squared. One important implication of this is that an increase in income inequality leads to an increase in the social mean of BMI. We will discuss the implications of these findings for the recent BMI dynamics in Japan.

\section{Definitions of obesity, severe obesity, and underweight}

Different from the international criterion for obesity provided by the World Health Organization (WHO), according to which a person is regarded 
as obese if he/she has a BMI $\geq 30$, the Examination Committee of Criteria for "Obesity Disease in Japan" (2002), affiliated to the Japan Society for the Study of Obesity (JSSO), provided a new criterion specific to Japan, according to which a person is regarded as obese if he/she has a BMI $\geq$ 25; detailed differences between the two criteria are summarized in Table 2. The new criterion was provided based on scientific evidence such as the finding that the average number of obesity-related disorders including hyperglycemia, dylipidemia, and hypertension exceeds 1.0 at a BMI of 25 and that there is a progressive increase in such disorders at a BMI $\geq 25$ (see "New Criteria," 2002). Since then, academic research, especially medical research, on the health of the Japanese as well as on the medical care policy of the Japanese government has been conducted based on the JSSO criterion.

In the text that follows, based on the JSSO criterion, we define obesity as a condition wherein a person has a BMI $\geq 25$ and severe obesity as a condition wherein a person has a BMI $\geq 30$ (see Table 2). Similarly, individuals with a $\mathrm{BMI}<18.5$ are classified as underweight. A BMI of 22, at which the probability of diseases becomes minimal (see "New Criteria," 2002), is regarded as standard or ideal.

Insert Table 2:

Definitions of obesity and underweight

The remainder of the paper is structured as follows: In Section 2, the relation between time discounting and caloric intake is discussed from the viewpoint of intertemporal resource allocation. In Section 3, after our Japanese survey data are presented, the time discounting data including discount rates and indicators for time discounting anomalies are constructed. Section 4 shows the regression results. Finally, Section 5 provides the conclusion.

\section{Time discounting and caloric intake behav- ior}

When we make intertemporal decisions including those on caloric intake, our subjective discount rate, a measure of time preference, plays a key role in determining how much of a resource is consumed for present gratification and how much is saved for future gratification. We hypothesize that interpersonal differences in BMI are, in part, related to those in time discounting. To investigate the effects of time discounting on BMI and hence on the degrees 
of obesity and underweight, we take into account three properties regarding time discounting: (i) the degree of impatience, (ii) hyperbolic discounting, and (iii) the sign effect.

\section{(i) Impatience}

A higher subjective discount rate implies a higher degree of impatience and hence a stronger preference for present consumption. In advanced countries, where the costs of caloric intake in terms of both money and time are so low that nutrition and calories that are biologically required for subsistence are almost freely available, those less patient with higher discount rates would tend to have higher BMI values and to have a higher probability of being obese. As in Komlos et al. (2004) and Smith et al. (2005), we hypothesize that persons with higher discount rates tend to have greater body mass.

\section{(ii) Hyperbolic discounting}

As a stylized fact, it has often been reported that people have high discount rates for very short delays whereas they have considerably lower discount rates for longer delays (e.g., Thaler, 1981 and Benzion et al., 1989). This implies that people are less patient in the case of immediate gratification than in the case of delayed gratifications in the distant future. Since the resulting discount factor is better described by a hyperbolic function of delay than an exponential one, the phenomenon is referred to as hyperbolic discounting. ${ }^{3}$

Hyperbolic discounting tends to lead people lacking adequate self-control to engage in time-inconsistent procrastination with regard to dieting and health care and consequently to overeating, which will harm their long-run interests (e.g., Ainslie, 2001). In theory, Cutler et al. (2003) stress that reductions in costs pertaining to food consumption due to recent technological advancements have been accelerating this time-inconsistent overeating, thereby increasing the prevalence rate of obesity. Chapman (1995) also points out that hyperbolic discounting gives rise to underinvestment in health capital. We hypothesize that persons with a stronger tendency toward hyperbolic discounting and hence with a stronger propensity toward procrastination tend to have a greater body mass.

\section{(iii) The sign effect}

\footnotetext{
${ }^{3}$ This phenomenon is sometimes referred to as the immediacy effect (e.g., Thaler, 1981; Benzion et al., 1989).
} 
Many studies have reported that losses are discounted at a lower rate than are gains. For example, Thaler (1981) finds that the discount rates for gains were 3 to 10 times higher than those for losses. Several of Thaler's subjects evidence negative discount rates for loss, implying that an immediate loss is preferred to a delayed loss of the same value. In Loewenstein (1988), his subjects' evaluations reveal that they are indifferent between receiving $\$ 100$ immediately and receiving $\$ 157$ in a year and are indifferent between losing $\$ 100$ immediately and losing $\$ 133$ in a year. This gain-loss asymmetry is referred to as the sign effect.

The sign effect makes people reluctant to borrow because persons who operate under this effect require a more favorable (i.e., lower) interest rate to borrow than they would to save (e.g., Loewenstein and Prelec, 1992). Similarly, in the case of the sign effect, people tend to try to control food consumption to avoid bearing various obesity-related costs in the future, such as the hardships associated with dieting and costs of medical care. We hypothesize that subjects operating under the sign effect are likely to have a smaller body mass.

\section{The data}

Our empirical research is based on the Japan Household Survey on Consumer Preferences and Satisfaction 2005 (hereafter, JHS05), conducted in February 2005. This survey is a project that is carried out as part of the Osaka University COE program, sponsored by the Ministry of Education, Culture, Sports, and Science and Technology of Japan. The JHS05 is a household survey, in which 6000 randomly selected Japanese respondents who are older than the age of 20 are requested to fill out questionnaires; out of the 6000 people, 2987 responded, and the proportion of male respondents was $47.0 \%$, with the average age of the respondents being 49.080. The survey contains various questions that enable us to elicit information about the respondents' attitudes toward time discounting and risk; their demographic, social, and economic attributes; and their health status including height and weight.

\subsection{BMI}

From the data on height and weight obtained from the JHS05, the respondents' BMI values are calculated by dividing weight in kilograms by height in meters squared. Since the JHS05 elicited self-reported data, the resulting BMI data may well contain an underreporting bias due to respondents' underreporting of weight and overreporting of height, as in Cawley (2004) and 
Chou et al. (2004). Every year, the Ministry of Health, Labour and Welfare of Japan measures the actual height and weight of thousands of randomly selected Japanese people and summarizes the data obtained from the survey by reporting the BMI distributions, by age, of the males and females. Since the sample sizes of the NSHN04 and JHS05 are sufficiently large, by comparing the age-based BMI distributions of our JHS05 data with those of the NSHN conducted in 2004 (hereafter, NSHN04; sample size: 7689), we could roughly examine whether or not the JHS05 data contain a self-reporting bias. ${ }^{4}$ If the presence of a bias is strongly suggested, it would be necessary to correct for it.

Figures 1(a) and (b) compare the BMI distributions obtained from the NSHN04 and JHS05 for the male (a) and female (b) samples; the histograms represent differences in relative frequencies (the "corrected data" will be demonstrated later). As seen from the figures, the JHS05 distribution is thicker than the NSHN04 distribution in the normal range $(18.5 \leqq \mathrm{BMI}$ $<25$ ), whereas for the ranges of underweight and, especially obesity, the JHS05 displays thinner tails than the NSHN04; all these observations suggest the possibilities of the presence of a self-reporting bias in the JHS04 data.

Insert Figures 1(a) and 1(b):

BMI distributions: NSHN04, JHS05, and corrected data.

Tables 3(a) through (d) statistically describe and compare the distributions, by age, of BMI and the prevalence rates of obesity, severe obesity, and underweight as revealed by the NSHN04 and JHS05 data sets, respectively. From this data, we can observe three tendencies. First of all, consistent with Figures 1 (a) and (b), the BMI mean, the obesity rate, and the severe obesity rate seem to reflect an underreporting bias. Particularly in the case of the data for females, the BMI means and the obesity rate as revealed by the JHS05 are significantly lower in many generations than those as revealed by the NSHN04 data. Consistent with this tendency, the sample standard deviations (SDs) of the females' BMI in the JHS05 are significantly smaller than those in the NSHN04. As for the male sample, although the bias is not as large as it is in the female sample, the obesity rates are smaller in the JHS05. Second, there is no difference between the rates of severe obesity

\footnotetext{
${ }^{4}$ The NSHN04 survey was conducted in November 2004, and the JHS05 survey was conducted in February 2005; therefore, the systematic differences in the two BMI data sets due to time difference can be regarded as negligible.
} 
among males in the two data sets. Third, although the prevalence rates of underweight in the JHS05 are slightly lower than those in the NSHN04, their downward bias does not seem to be substantial.

Insert Tables 3 (a) through (d):

By-age distributions of body mass: NSHN04, JHS05, and corrected data

Based on these observations, we correct for the underreporting bias in the female sample by employing the following procedure, which is a modified version of the procedure proposed in the literature (e.g., Cawley, 2004; Chou et al., 2004; Cawley and Burkhauser, 2006; and Michaud et al., 2007). ${ }^{5}$ From the self-reported BMI data in generations $i(i=20,30,40,50,60)$ obtained from the JHS05, we specify a quadratic function, $f_{i}(x)=a_{i} x^{2}+b_{i} x+c_{i}$ for $x \geqq 22$, to obtain corrected BMI data. The coefficients $a_{i}, b_{i}$, and $c_{i}$ are determined such that the function satisfies

(1) $f_{i}\left(x_{i}^{*}\right)=25$;

(2) $f_{i}\left(x_{i}^{* *}\right)=30$; and

(3) $f_{i}(22)=22$,

where $x_{i}^{*}$ and $x_{i}^{* *}$ represent the critical BMI values by which to define obesity and severe obesity for generation $i$ that equilibrate the prevalence rates of obesity and severe obesity in JHS05 to the corresponding prevalence rates in the NSHN04. For the sample of females in their 50s, $x_{50}^{*}$ is obtained as 24.24, which means that for the female obesity rate in the JHS05 data to equal that in the NSHN04 data, the critical BMI value that defines obesity should be lowered from 25 to 24.24 . The adjusted critical BMI $x_{50}^{* *}$ for severe obesity amounts to 28.67 .

Conditions (1) and (2) ensure that the corrected BMI distribution generates the same obesity and severe obesity rates as those in the NSHN04.

\footnotetext{
${ }^{5}$ Chou et al. (2004) followed Cawley's (2004) procedure when correcting for the underreporting biases in the original self-reported data by (1) estimating the quadratic relations between actual and self-reported values of weight and height by using the Third National Health and Nutrition Examination Survey (NHANES III), U.S.A., and (2) applying the estimated relations to their American self-reported data (the BRFSS) pertaining to weight and height to obtain bias-corrected data and to compute bias-corrected BMI. Michaud et al. (2007) applied the quadratic correction function estimated by Cawley and Burkhauser (2006) to their European self-reported data. In Japan, there is no data set that contains both actually measured and self-reported data of height and weight. However, it might be questionable to directly apply Cawley and Burkhauser's estimated correction function to the Japanese data because the BMI distribution in Japan and the definition of obesity therein both differ from those in the American or European countries (see the Examination Committee, 2002).
} 
Condition (3) is the assumption that since a BMI of 22 is thought of as the healthiest from the medical viewpoint, ${ }^{6}$ people with $\mathrm{BMI} \leqq 22$ could be regarded as having no incentive to underreport their weights and/or to overreport their height, and hence, would have no tendency to underreport their BMI values. The corrected values of the female BMI for $x \geqq 22$ are computed by using the quadratic functions obtained for the corresponding generations, whereas for $x<22$, no adjustment is made since no serious bias is observed for the range of small BMI values.

The male BMI data are adjusted in a similar manner except that no adjustment is made for $x>30$ since, as seen from Table $3(\mathrm{c})$, the prevalence rate of severe obesity in the JHS05 does not differ significantly from that in the NSHN04. There seems to be no strong incentive for severely obese males to underreport their BMI.

The body mass distributions of the corrected data are depicted in Figures 1(a) and (b) and are summarized statistically in Tables 3(a) through (d). They show that the correction eliminates, to a great extent, the underreporting bias. By construction, the biases in the prevalence rates of obesity for males and females as well as those in the prevalence rate of severe obesity for females are almost completely corrected for. The differences between the BMI mean revealed by the corrected JHS05 and that revealed by the NSHN04 are statistically insignificant for almost all the generations. The downward biases in the standard deviation of BMI are also reasonably reduced..$^{7} 8$

\subsection{Eliciting discount rates}

In the JHS05, the respondents' discount rates are measured by asking five questions on intertemporal choice under alternative conditions. As in previous surveys (e.g., Harrison et al., 2002 and Borghans and Golsteyn, 2006), the respondents are told to choose between two options, "A" and "B." For example, they are asked to choose between "A" — receiving JPY 10,000 in 2 days and "B" - receiving JPY 10,000 plus a certain amount JPY $\alpha$, say JPY 10,038 , in 9 days. Here, choosing the delayed receipt "B" instead of "A" implies receiving $20 \%$ of the annual interest rate. In each question, eight such queries with alternative $\alpha$ values, from small to large, and hence with alternative imputed interest rates, from low to high, were asked in rows of a

\footnotetext{
${ }^{6}$ See Examination Committee of JSSO (2002).

${ }^{7}$ However, the corrections of the downward bias in the SDs remain insufficient for males in their 20 s and 30 s and for females in their 30 s and 40 s.

${ }^{8}$ The main empirical results that are reported in Section 4 do not differ substantially even when the uncorrected BMI data are used when conducting the regression analysis below. For the empirical results in the case of the uncorrected data, see the Appendix.
} 
question table.

Table 4 represents the query QUESTION 1, wherein the amount of receipt for option "A" is specified as JPY 10,000 and the imputed interest rate for option "B" changes from $-10 \%$ to $300 \%$. The respondents are expected to choose option "A" at low interest rates, whereas as the imputed interest rate rises, they are expected to switch to option "B" at a certain critical high rate. The individual respondents' discount rates can be inferred by estimating the interest rate at which the delayed receipt of option " $\mathrm{B}$ " is indifferent to the more immediate receipt of option "A." Note, however, that the elicited discount rates are associated with the particular choice conditions, for example, 2 days versus 9 days, the amount JPY 10,000 for option "A" in QUESTION 1 .

Insert Table 4:

Question to elicit discount rates: An example (QUESTION 1 for $\mathrm{DR}_{1}$ )

To detect time discounting anomalies, five questions are developed by controlling for (i) money amounts for option "A" as JPY 10,000 or JPY 1 million; (ii) time horizons for "A" as 2 days, 1 month, or 90 days; (iii) time delays as 7 days or 12 months; and (iv) receipt or payment. In the "payment" question, QUESTION 5, the respondents are asked to choose either "A" paying JPY 1 million in 1 month or "B" - paying JPY 1 million + some amount in 13 months, from which acceptable interest rate payments to delay a 1 million payment for 12 months are elicited.

From each question, we obtain raw response data, which indicate the interest rates between which each respondent switched his/her choice from option "A" to "B." Some subjects, however, stuck to option "A," regardless of the interest rates that were offered. To elicit the respondents' discount rates from these raw data, we follow Kimball et al. (2005) in estimating a log-normal distribution for the cross-respondent distribution of gross discount rates. From the estimated distribution, each respondent's gross discount rate for a certain question, that is, a certain question table, is estimated as an expected value conditional on the fact that the respondent changes his/her choice between certain interest rates. The descriptive statistics of the elicited discount rates, together with the choice conditions under which they are elicited, are summarized in Table 5 , where $\operatorname{DR} i(i=1, \ldots, 5)$ represent the discount rates that are estimated from QUESTION $i$.

Insert Table 5:

Elicited discount rates under alternative choice conditions 
To investigate the effect of impatience on body mass, we construct DRSTD, which represents the simple average of the standardized values of the elicited discount rates $\operatorname{DR} i(i=1, \ldots, 5)$ :

$$
\operatorname{DRSTD}=(1 / 5) \Sigma_{i=1}^{5}\left(\mathrm{DR}_{i}-E\left(\left(\mathrm{DR}_{i}\right)\right) / \sigma\left(\mathrm{DR}_{i}\right)\right.
$$

where $E(\cdot)$ and $\sigma(\cdot)$ represent sample means and standard deviations. For $E\left(\mathrm{DR}_{i}\right)$ and $\sigma\left(\mathrm{DR}_{i}\right)$, see Table 5 . Table 6 summarizes the definitions of variables that are used in the analysis below as well as their basic statistics. ${ }^{9}$ It is hypothesized that, other things being equal, the respondents' body mass depends positively on the impatience index DRSTD.

Insert Table 6:

Definitions of variables and basic statistics

\subsubsection{Time discounting anomalies}

By comparing the mean values of the elicited discount rates, we can examine whether our average respondent displays the aforementioned two anomalies of time discounting. First, on average, hyperbolic discounting or the immediacy effect is not observed since the mean of the discount rate $\mathrm{DR}_{1}$, imputed from the immediate future choice (i.e., 2 days or 9 days), is not significantly higher than $\mathrm{DR}_{2}$, which is applied to a more distant future choice (i.e., 90 days or 97 days). Second, the discount rate $\mathrm{DR}_{4}$ applied to future receipts is significantly higher than $\mathrm{DR}_{5}$, the DR used for the discounting of future payments; this implies that our average respondent displays the sign effect. ${ }^{10}$

To examine the effects of the time discounting anomalies on the respondents' body mass, we construct the binary indicator HYPERBOL for hyperbolic discounting, and the binary indicator SIGN for the sign effect, where, for example, HYPERBOL $=1$ if $\mathrm{DR}_{1}>\mathrm{DR}_{2}$, and HYPERBOL $=0$ otherwise. From the mean values of HYPERBOL and SIGN, shown in Table 6 , the proportions of the respondents who display the anomalies are $61.1 \%$ (hyperbolic discounting) and $88.5 \%$ (the sign effect). Our hypothesis is that,

\footnotetext{
${ }^{9}$ Although the standardized average DRSTD of the elicited discount rates should theoretically satisfy $E($ DRSTD $)=0$ and $\sigma(\mathrm{DRSTD})=1$, neither of the equalities is fulfilled, as seen in Table 6 . This stems from the fact that the number of effective responses differ in the five discount rate questions.

${ }^{10} \mathrm{In}$ addition, although we have not included the results of the $t$ test in Table $5, \mathrm{DR}_{3}$, the discount rate for JPY 10,000 is significantly higher than $\mathrm{DR}_{4}$, applied for JPY 1 million, implying that people are more patient in the case of larger amounts than in the case of smaller amounts. This tendency is called the magnitude effect (e.g., Benzion et al., 1989 and Frederick et al., 2002).
} 
other things being equal, the respondents' body mass is positively related to HYPERBOL and negatively related to SIGN.

\subsubsection{Proxies for impatience and procrastination}

To capture the effects of impatience and hyperbolic discounting, we also construct proxy variable DEBTIMP for impatience and PROCR for hyperbolic discounting. To measure respondents' degrees of hyperbolic discounting or procrastination, the JHS05 survey asks them to indicate, on a 5-point scale ranging from 1 to 5 , what used to be the extent of their tendency to procrastinate doing homework assignments in the summer vacations during their high school days. ${ }^{11}$ Variable PROCR represents the response data to this question, wherein a larger value implies a stronger tendency toward procrastination or hyperbolic discounting.

Besides DRSTD, we estimate DEBTIMP, as a proxy measure of the degree of impatience, from the respondents' debt holding behavior. In the JHS05, the respondents are asked to indicate whether they have debts other than housing loans. Let DEBT denote a binary indicator for the debt holding. The debt holding DEBT is expected to depend on time discounting in three ways: by means of (i) impatience, where high impatience implies a high probability of debt holdings; (ii) hyperbolic discounting, which causes people to procrastinate carrying out saving plans, leading to excessive debt holdings (see Laibson, 1997, 1998); and (iii) the sign effect, which makes people reluctant to pay interest in the future, thereby inducing "borrowing aversion" behavior (see Loewenstein and Prelec, 1992).

Impatience proxy DEBTIMP is the standardized residual of Prob(DEBT $=1$ ) after regressing it using a probit model on the following: PROCR, as a proxy for (ii); SIGN, the binary indicator for (iii); and other control variables capturing the degree of risk aversion (RISKAV), per capita household income (INCOME and INCOME^2), the expected percentage change of income in a forthcoming year ( $\triangle \mathrm{INCOME}$ ), and ages (AGE and AGE squared). The risk aversion index RISKAV is constructed by subtracting from $100 \%$ the respondents' responses to the question "When you go out, how high a probability of rainfall makes you carry an umbrella?" A high RISKAV value, say that of $90 \%$, implies that the respondent carries an umbrella even when it is very unlikely to rain, say if there is a $10 \%$ probability of rainfall.

The result of the first stage probit regression for Prob(DEBT $=1)$, together with that of the regression with impatience measure DRSTD added

\footnotetext{
${ }^{11}$ In Japanese elementary and high schools, students are usually given many different homework assignments during the summer vacations.
} 
to the set of the explanatory variables, are shown in Table 7, where the marginal effect of each explanatory variable on the probability of the respondent being a debtor is listed. As shown in the second column, which depicts the first probit model without DRSTD as a regressor, the coefficients for all the explanatory variables are significant. In particular, as predicted by theory, debt holding is positively related to the tendency to procrastinate PROCR, and negatively related to the sign effect SIGN, where both the coefficients are significant at the $10 \%$ level. ${ }^{12}$ As seen in the third row of the table, the result is robust, except that the P-value for PROCR becomes a little lower than $10 \%$ when we introduce, as an impatience measure, the standardized mean of the elicited discount rates DRSTD to the set of explanatory variables.

\section{Insert Table 7:}

Time discounting and debt holdings

The proxy DEBTIMP for impatience is constructed by standardizing the residuals of the first regression model, that is, the model that does not include the impatience variable as a regressor. To check the relevancy of using DEBTIMP as an impatience proxy, Table 8 examines correlations of DEBTIMP with the discount rates elicited from each respondent and DRSTD. In fact, the impatience proxy shows significant positive correlations with each of the respondent's discount rates and DRSTD. This is consistent with the fact that, as is seen in the third column of Table 7, the impatience measure DRSTD has a positive and highly significant correlation with debt holdings.

Insert Table 8:

Correlations between impatience proxy (DEBTIMP) and elicited discount rates

\section{Results}

For explanatory variables of the respondents' body mass, we take into account (i) preference factors regarding time discounting and risk aversion; (ii) demographic factors, including gender (MALE), education (UNIV), and age

\footnotetext{
${ }^{12}$ Negative coefficients of risk aversion RISKAV could be interpreted as capturing the tendency that the more risk averse hold smaller debts to avoid the risk of bankruptcy. Debt holding is shown to be quadratically correlated with age and income.
} 
(AGE), where MALE and UNIV are binary indicators for males and university graduates, respectively; and (iii) economic factors such as per capita household income INCOME and working hours (WORKHOUR). Since there is uncertainty regarding how much increase in BMI is caused by a certain amount of excessive caloric intake, we hypothesize that more risk-averse respondents are likely to have a smaller BMI value.

To capture possible non-monotonic correlations, we add AGE squared, INCOME squared, and the square root of WORKHOUR to the set of explanatory variables. As for working hours, Ohtake (2005) conjectured that people's BMI is correlated with their working hours under two circumstances. The first circumstance is that of overworking. Working for long hours is bound to lead to irregular and unhealthy eating - for example, skipping breakfast, eating dinner late, and eating out frequently - which causes obesity. Second, especially in the case of women who work part-time jobs, working hours function as a means to control caloric intake. With these positive and negative effects of increases in working hours, BMI may have a nonmonotonic correlation with working hours. The empirical validity of this assumption is examined by including WORKHOUR and its square root as explanatory variables. ${ }^{13}$

We also control for smoking habits SMOKING, which indicates the strength of the respondents' smoking habit on a 6-point scale. Since smoking harms one's health and thereby reduces body mass, BMI is expected to be negatively correlated with SMOKING. Note that, as is often stressed in the literature (Becker and Murphy, 1988 and Khwaja et al., 2007), less patient people are likely to smoke more since the future loss in utility caused by the unhealthy behavior is likely to be discounted more intensively. Unless the smoking habit is controlled for, the correlation between BMI and time discounting might be underestimated.

We estimate two regression models: model (1) and model (2). In model (1), we use time discounting variables elicited from hypothetical intertemporal monetary choices, namely, DRSTD, as an impatience measure, and HYPERBOL as a measure for hyperbolic discounting (or procrastination). Due to a domain effect, however, these time discounting variables constructed from hypothetical monetary choices might not succeed in capturing the correlation between time discounting and BMI. ${ }^{14}$ Thus, instead, model (2) re-

\footnotetext{
${ }^{13}$ By examining Japanese cross-sectional data in 2000, Suzuki (2007) reported that both the BMI and the probability of being obese are positively and significantly correlated with working hours, thereby partially supporting Ohtake's conjecture.

${ }^{14}$ For example, Chapman (1995) report that monetary discount rates do not have a strong explanatory power for intertemporal choices regarding health investments. In fact, in Borghans et al. (2006), monetary discount rates elicited from hypothetical pecuniary
} 
gresses body mass variables including BMI on the proxies for time discounting, namely, DEBTIMP for impatience and PROCR for hyperbolic discounting (procrastination). Other explanatory variables, including the indicator SIGN for the sign effect, are common to the two models. The models are estimated in the all, male, and female samples in order. The OLS method is used for the BMI regression and the binary probit method is used to estimate the probabilities of being obese, severely obese, and underweight.

\subsection{BMI}

\subsubsection{Preference factors}

Table 9 summarizes the results of the OLS regressions for BMI. In model (1), as is predicted by theory, BMI displays significantly positive correlations with impatience (DRSTD) for the full sample and significantly negative correlations with the sign effect (SIGN) for the full sample and the female sample. In the full sample, for example, a discount rate that exceeds the average by one unit of SD, ceteris paribus, leads to a BMI that is around .300 higher than the average. In this sample, the BMI of the average respondent who displays the sign effect is around .578 smaller than that of respondents who do not display the sign effect. However, positive effects of hyperbolic discounting HYPERBOL are not significant in model (1). As a whole, the effects of time discounting on BMI are not strongly detected from model (1).

\section{Insert Table 9: \\ BMI regressions}

In model (2), in contrast, BMI displays fairly significant correlations with the three time discounting variables. In particular, for the full and female samples, the coefficients of all the time discounting variables, namely, impatience (DEBTIMP), procrastination (PROCR), and the sign effect (SIGN), have expected signs and are fairly significant. Also, in the male sample, the positive effect of procrastination is significant.

To quantitatively evaluate the impacts of the time discounting variables reported in Table 9, Table 10 computes the normalized impacts by dividing the marginal effects in model (2) by the sample mean or the SD of BMI. The column " $\Delta$ impatience" reports the impacts of an increase in the average of the discount rates $\mathrm{DR}_{i}$ by one unit of the $\mathrm{SD}$, that is, a unit increase

choices do not display as strong correlations with BMI as do other impatience proxies that are constructed from responses to behavioral and/or psychological questions. 
in DRSTD; the column " $\Delta$ procrastination" shows the effects of an increase in the propensity to procrastinate doing homework from the weakest degree $(\mathrm{PROCR}=1)$ to the strongest degree $(\mathrm{PROCR}=5)$; and the column " $\Delta$ sign effect" represents the effects of the presence of the sign effect $(\mathrm{SIGN}=1)$, compared to the case without the sign effect $(\mathrm{PROCR}=0)$. As seen from the table, procrastination and the sign effect have certain impacts on the females' BMI. Female respondents with the strongest degree of procrastination are, ceteris paribus, heavier than those with the weakest degree of procrastination by $33.78 \%$ of the sample SD. The difference in BMI between female respondents who do and do not display the sign effect amounts to $-23.58 \%$ of the sample SD. Relative to these impacts, those of impatience on BMI are not so large, though.

Insert Table 10:

Impacts of time discounting variables on BMI: The case of Model (2)

In sum, both the models show that, especially for the full and female samples, BMI shows expected correlations with impatience and the sign effect. A significant positive correlation between BMI and hyperbolic discounting is also consistently observed in all the samples when the tendency to procrastinate doing homework is used as a proxy for the degree of hyperbolic discounting.

The dependence of BMI on risk aversion (RISKAV) is, as is expected, significantly negative for the full and male samples in both models. For example, the BMI of a male respondent who is risk averse such that his critical likelihood of carrying an umbrella is $10 \%$ higher than the average is, ceteris paribus, lower than that of the average male by .100 (model (1)) to .103 (model (2)). For the female sample, however, the observed negative correlations between BMI and RISKAV are insignificant.

\subsubsection{Demographic factors}

With regard to demographic variables, males are significantly heavier than females, which is in contrast to the case in the American and European countries. ${ }^{15}$ In both models and for both samples, BMI quadratically depends

\footnotetext{
${ }^{15}$ By using the U.S. samples, Komlos et al. (2004) show that the average BMI of and the obesity rate among females are larger than those of males. Borghans and Golsteyn (2006) detect the same tendency in the Dutch samples. By using the U.S. survey data, Chou et al. (2004) report that males' BMI is larger than that of females, whereas the obesity rate among females is higher than that among males.
} 
significantly on age, such that BMI increases with age at decreasing rates until a critical age, after which it decreases at increasing rates. The critical peak is 53.25 (i.e., $0.213 /\left(2^{*} 0.002\right)$ ) years (model $(1)$ ) or 52.00 (model $(2)$ ) for males, and 64.00 years (model (1)) or 65.75 (model (2)) for females. ${ }^{16} \mathrm{As}$ seen in Table 3(a), if the other explanatory variables are not controlled for, males' BMI peaks when they are in their 40s, which is earlier than the age at which they are at their heaviest (i.e., 53.25 years (model (1)) or 52.00 (model (2)); on the other hand, females' BMI peaks when they are in their 60s, which is consistent with the estimate given by the multivariate regression. A high level of education (UNIV) is not found to have a significant correlation with BMI.

\subsubsection{Economic factors}

In the full and female samples, the coefficients of per capita household income (INCOME) are significantly negative and those of the income squared are significantly positive in both models, which implies that the BMI-income correlation could be non-monotonic. In fact, in both samples, the critical income level at which BMI reaches its lowest level is higher than the average income level, but still remains within the observed income range. For example, Figures 2(a) and (b) depict the relations in the female sample between per capita household income and BMI, estimated by models (1) and (2), respectively, when the effects of other factors considered in the models are controlled for. The critical income level estimated from the female sample regression is 3.785 (i.e., JPY .598/(.079*2)) million for model (1). Since the $\mathrm{SD}$ in the female sample is estimated as 1.503, the critical income exceeds the mean income by an SD of 1.094. For model (2), the critical income level at which the female BMI reaches its lowest level is estimated as JPY 3.912 million, which exceeds the mean income by an SD of 1.178 .

Figure 3 depicts the resulting non-monotonic relation between the female respondents' income and the income elasticity of BMI, where the females' income elasticity of BMI in each income quintile, evaluated at its average income and average BMI, is plotted. ${ }^{17}$ In both models (1) and (2), it is shown that the female respondents in the highest income quintile show pos-

\footnotetext{
${ }^{16}$ For the full sample, BMI peaks at an age of 61.00 years in model (1) and at an age of 60.00 years in model (2); these ages are slightly higher than 57, which Chou et al. (2004) obtained by using U.S. data.

${ }^{17}$ Letting $\beta_{1}$ and $\beta_{2}$ denote the estimated coefficients of INCOME and INCOME^2, the income elasticities of BMI evaluated at the average in the $i$ th income quintiles $(i=1, \cdots, 5)$ are given by $E_{i}(\mathrm{INCOME})\left(\beta_{1}+2 \beta_{2} E_{i}(\mathrm{INCOME})\right) / E_{i}(\mathrm{BMI})$, where $E_{i}(\cdot)$ represent averages in the $i$ th income quintiles.
} 
itive income elasticities of BMI (i.e., $2.8 \%$ and $2.7 \%$ for models (1) and (2), respectively), whereas those in the lower income classes show negative income elasticities. ${ }^{18}$ The non-monotonic income-BMI relation is in contrast with the monotonic, negative correlations between income and BMI that have been reported in the literature. ${ }^{19}$

Insert Figures 2(a) and (b):

Income and BMI: Females (model (1) and (2), respectively)

Insert Figure 3:

Income Elasticities of BMI in Income Quintiles

It is noteworthy that, with the significant positive effect of per capita household income squared, the sample mean of BMI depends positively on the degree of income inequality measured by the sample variance of per capita income. Because $E\left(\mathrm{INCOME}^{2}\right)=\left(\frac{N-1}{N}\right) \sigma(\mathrm{INCOME})^{2}+E(\mathrm{INCOME})^{2}$, where $N$ denotes the number of samples, the sample mean $E(\mathrm{BMI})$ depends on $\sigma(\mathrm{INCOME})^{2}$. With a positive coefficient of $\mathrm{INCOME}^{2}$, a mean-preserving increase in income variance is thus predicted to lead to an increase in the sample mean of BMI. This relation might have an implication in explaining the recent decline in BMI among females in Japan since there has been a decrease in the income inequality of Japanese females. ${ }^{20}$ For example, based on the results of the female sample regression of model (1), a decrease by 0.1 in the variation coefficient of per capita income $\sigma$ (INCOME) $/ E($ INCOME) would decrease the females' mean BMI by $0.054,{ }^{21}$ which amounts to a $23.7 \%$

\footnotetext{
${ }^{18}$ The females' income elasticities of BMI, evaluated at their overall average, are computed as -0.025 for model (1) and -0.031 for model (2), which are close to Chou et al.'s (2004) estimate of -0.03 of the income elasticity of BMI in their full sample. In the case of the full sample, however, our estimates become around -0.01 for both the models, reflecting the tendency of the males' BMI to be inelastic to income.

${ }^{19}$ Chou at al. (2004) also report that BMI is quadratically related to household income. In their result, however, the critical income level is so high that BMI almost monotonically decreases over the actual range of their income sample.

${ }^{20}$ Actually, from our JHS2004 and JHS2005 data, the variation coefficients of the females' per capita household income are 0.793 in 2004 and 0.702 in 2005, implying that there was a 0.047 decrease in the variation coefficient during the 2 years.

${ }^{21}$ The sample mean of BMI can be expressed in terms of variation coefficient $v \equiv$ $\sigma(\mathrm{INCOME}) / E(\mathrm{INCOME})$ as

$$
E(B M I)=\mathrm{const}+\beta\left(\frac{N-1}{N}\right) E(\mathrm{INCOME})^{2}\left(v^{2}+1\right)+\cdots,
$$
}

where $\beta$ denotes the coefficient of $\mathrm{INCME}^{\wedge} 2$ in the regression result; and $\frac{N-1}{N} \simeq 1$ for our sample size. 
decrease in females' BMI from 2003 (average BMI (age $\geq 20$ ): 22.62) to 2004 (22.39). ${ }^{22}$ In the case of model (2), the decrease in BMI predicted by a 0.1 decrease in $\sigma$ (INCOME) $/ E$ (INCOME) equals 0.063 , which amounts to $27.3 \%$ of the actual BMI decrease during the 2003-04 period. ${ }^{23}$.

In Table 9, the respondents' BMI values are also shown to have a nonmonotonic correlation with working hours in the full and female samples. Consistent with what Ohtake (2005) conjectures, with positive coefficients of WORKHOUR and negative coefficients of its square root, the correlation is negative for small WORKHOUR values, whereas it becomes positive for WORKHOUR values that are larger than some critical levels. Figure 4 depicts the resulting non-monotonic working hour elasticities of BMI, where the critical working hour values at which the elasticity of BMI shifts from negative to positive are computed as 12.84 hours a week for model (1) and 12.38 hours a week for model (2). Although the working hour-BMI correlation is insignificant in the male sample, the significant non-monotonic correlation between working hours and BMI persists in the full sample, where the critical working hour values are 11.21 for model (1) and 11.65 for model (2).

Insert Figure 4:

Females' working hour elasticities of BMI

\subsection{Obesity and severe obesity}

Let OBESITY and SEVERE OBESITY be binary indicators for obesity and severe obesity, respectively. By using binary probit models, we estimate the marginal effects on the probabilities Prob (OBESITY $=1)$ and Prob (SEVERE OBESITY $=1$ ) of the same explanatory variables for BMI as in models (1) and (2). Tables 11 and 12 show the results for obesity and serious obesity, respectively.

As for obesity, the estimated marginal effects of the impatience variables DRSTD and DEBTIMP are both positive and reasonably significant in both models. In the full sample, the respondents who are less patient by an SD of one unit than the average are obese with a $5.8 \%$ higher probability in model (1) and with a $2.8 \%$ higher probability in model (2). Note that these impacts

\footnotetext{
${ }^{22}$ For the Japanese BMI distribution in 2003, see the NSHN03.

${ }^{23}$ However, since a magnitude of 0.1 is unusually large as an increase in the variation coefficient of income, the effect of income inequality seems quantitatively too small to explain the recent decrease in the body mass of females. In fact, during the 2003-04 period, a 0.047 decrease in the variation coefficient of income is observed in the JHS data, which can explain only $7.4 \%$ (model 1 ) to $8.5 \%$ (model 2 ) of the decrease $(0.23)$ in the females' BMI reported by the NSHN during the 2 years.
} 
are not that small compared with the overall obesity prevalence rate $(24.3 \%)$, that is, the unconditional probability of being obese.

With regard to the other discounting variables, the result of model (1) is poor, whereas in model (2), the effect of procrastination (PROCR) on the obesity probability is positive at the $1 \%$ significance level in the full and female samples. In model (2), the probability of respondents with the strongest tendency to procrastinate $(\mathrm{PROCR}=5)$ being obese is roughly $10.8 \%$ (2.7\% times 4) higher than the corresponding probability of those with no tendency to procrastinate $(\mathrm{PROCR}=1)$ in the full sample and is $12.0 \%$ higher in the female sample. The effects are quantitatively not small, compared with the unconditional probabilities of being obese, measured by the corresponding obesity prevalence rates $(24.3 \%$ and $19.5 \%$ for the full and female samples, respectively). The sign effect, however, is not significant.

As in the BMI regressions, non-monotonic correlations with age, per capita household income (INCOME), and working hours per week (WORKHOUR) are significant for the full and female samples in both models. For example, the probability of being obese in the full sample is the lowest at JPY 3.389 million of INCOME for model (1) and at JPY 3.526 million for model (2); these values are reasonably close to the corresponding critical values of income in the BMI regressions.

Insert Table 11:

Binary probit regressions of obesity

The probability of being severely obese has a significant negative correlation with the sign effect in the full and female samples, implying that respondents who do not display the sign effect are likely to be severely obese. For example, in model (1), the probability of respondents who do not display the sign effect being severely obese is $2.7 \%$ higher than the corresponding probability for those who do display the sign effect in the full sample, and is $4.2 \%$ higher than the corresponding probability for those who display the sign effect in the female sample. The increases in the probability due to the absence of the sign effect are as large as, or even larger than the unconditional probabilities of being severely obese (3.1\% and $1.4 \%$ for the full and female samples, respectively).

Although the effects of hyperbolic discounting in model (1) are insignificant, the effects of homework procrastination PROCR in model (2) are significantly positive for the full and male samples. In particular, compared with the males' unconditional probability of being severely obese $(3.6 \%)$, the 
marginal effect of PROCR (1.1\%) on the probability of being severely obese is considerable.

Insert Table 12:

Binary probit regressions of severe obesity

\subsection{Underweight}

Table 13 reports the results on underweight. In the full and female samples, consistent with our hypothesis, models (1) and (2) show that the probability of being underweight has a significantly positive correlation with the sign effect. For both models, respondents displaying the sign effect belong to the underweight group with a $4 \%$ higher probability in the full sample, and with a $5 \%$ higher probability in the female sample, than those who did not display the effect. Again, the effects are large, compared to the corresponding unconditional probabilities of being underweight (i.e., $8.7 \%$ and $9.5 \%$ in the full and female samples, respectively). In model (2), procrastination has a significant negative effect on the probability of being underweight in the full and female samples.

Aging has quadratic effects on the underweight probability for the full and male samples. In the full sample, the probability of being underweight reaches its lowest level at around 52.5 years (model (1)) or 55.5 years (model (2)). The probability of females being underweight has a significant nonmonotonic correlation with per capita household income INCOME with positive coefficients on INCOME squared, where the probability is the lowest at an income of JPY 3.455 million for model (1) and JPY 3.422 million for model $(2) \cdot{ }^{24}$

Insert Table 13:

Binary probit regressions of underweight

Finally, by using the above results in the full sample for model (2), Table 14 summarizes the impacts of differences in the time discounting variables on the probabilities of being obese, severely obese, and underweight, wherein " $\Delta$ impatience," " $\Delta$ procrastination," and " $\Delta$ sign effect" are the same as in

\footnotetext{
${ }^{24}$ The fact that the females' BMI and obesity also show quadratic curves in INCOME suggests that the sample SDs of BMI stratified by income classes will form a U-shaped curve. Actually, the female sample SDs of BMI for the first to fifth income quintile groups are 3.584, 3.331, 2.761, 3.221, and 3.248, respectively, which form a U-shape, as expected.
} 
Table 10. All the impacts have expected signs, and many of them are significant. Compared with the corresponding unconditional probabilities, the magnitudes of the impacts of these time discounting variables are not negligible. $^{25}$

\section{Insert Table 14:}

Impacts of time discounting variables on Probs of being obese, severely obese, and underweight: The case of Model (2) in the full sample

\section{Conclusions}

Motivated by the empirical fact that debtors are more likely to be obese than non-debtors, we hypothesized that, as in the case of debt holdings, interpersonal differences in body mass are related to interpersonal differences in time discounting as well as to differences in other demographic and economic factors. It has been partially (especially in the female sample) confirmed that time discounting affects body mass through impatience, hyperbolic discounting or procrastination, and the sign effect. Caloric intake behavior and the resulting body mass formation can thus be thought as determined as an intertemporal decision-making. An important policy implication is that the obesity rate can be affected by changing the intertemporal structure of the costs and benefits of obesity, especially that of medical costs.

Body mass has also been found to have a non-monotonic correlation with age, per capita household income, and working hours. In particular, the quadratic curve estimated between per capita household income and BMI implies that an increase in income inequality leads to an increase in the social average of BMI, whereas an increase in the average income lowers the average BMI.

Our regression models, however, do not have high explanatory power. The adjusted $R$-squared of the BMI regression is, at most, $11.8 \%$, and the models can explain only around $23 \%$ of the observed cross-sectional covariation between BMI and debt holding, measured by the sample covariance between $\mathrm{BMI}$ and DEBT. One possible reason for this is that genetic factors have dominant effects on BMI (e.g., Cutler and Glaeser, 2005). Another shortcoming may be that we failed to take into account interpersonal or regional

\footnotetext{
${ }^{25}$ These results remain unchanged even when the probabilities of being obese, severely obese, and underweight are jointly estimated by estimating multivariate probit models with correlated error terms. For the results of the multivariate probit regression, see the Appendix.
} 
differences in food prices. ${ }^{26}$

Future research would need to extend the analysis to a panel analysis so as to explain recent BMI dynamics in Japan. As reported by Borghans and Golsteyn (2006), it may be difficult to explain time series changes in BMI by changes in consumer preferences including time preference. Changes in economic factors such as income, working hours, food prices, and medical costs could be considered as more important.

\footnotetext{
${ }^{26}$ However, even when the effects of the regional and occupational differences are controlled for by adding the prefecture and occupation dummies to the set of the explanatory variables, the main results do not change substantially. For the estimation results with the prefecture and occupation dummies, see the Appendix.
} 


\section{APPENDIX}

To check the robustness of our main results that are obtained in the text, this Appendix reports the regression results in the following alternative cases:

A Incorporating prefecture and occupation dummies,

B Jointly estimating the probabilities of being obese, severely obese, and underweight by estimating multivariate probit models that allow correlations among error terms, and

C Using the uncorrected body mass data.

\section{A Incorporating prefecture and occupation dummies}

Our respondents' body mass could depend on regional and/or occupational factors. For example, the relative prices of various foods, and hence those of a calorie differ among regions. In the text, we have not controlled for any regional or occupational factors. The JHS contains the data of the respondents' residential prefectures (numbered 1 (Hokkaido) to 48 (Okinawa)) and occupations (numbered 1 (office workers) to 13 (others)). By constructing 47 of prefecture dummies and 12 of occupational dummies to add to the set of the explanatory variables, the same models as in Tables 9 (BMI) and 11 (OBESITY) to 13 (UNDERWEIGHT) are estimated. The results are reported in Table A1 through A4, where the coefficients of the prefecture and occupation dummies are omitted.

Insert Table A1:

BMI regression with prefecture and occupation dummies

Insert Table A2:

Obesity probit regression with prefecture and occupation dummies

Insert Table A3:

Severe obesity probit regression with prefecture and occupation dummies 
Insert Table A4:

Underweight probit regression with prefecture and occupation dummies

Although the significance levels of the estimated coefficients of some variables become weaker (e.g., the coefficients of DEBTIMP and PROCR of the BMI regression in Table A1), the results, as a whole, do not change considerably from those in the text. In many cases, the values of the $R$ squared or those of the log-likelihood improve.

One problem in these regressions is that, especially in the case of severe obesity and underweight, compared with the number of severely obese or underweight respondents, too many explanatory dummy variables are incorporated, ${ }^{27}$ so that we cannot help excluding redundant dummy variables from the data. Consequently, the number of the samples are unnecessarily reduced in these regressions (e.g., In Table A3, only 1192 samples are used in Model (1) and only 1131 in Model (2), whereas in Table 12, 1658 and 1629 samples are used in Models (1) and (2), respectively). To avoid this problem, the prefecture and occupation dummies have not been controlled for in the analysis in text.

\section{B Estimating multivariate probit models}

By construction, the binary indicators OBESITY and SEVERE OBESITY necessarily have a negative correlation; and UNDERWEIGHT necessarily has negative correlations with OBESITY and SEVERE OBESITY. These correlations may well be retained after controlling for the effects of the explanatory variables in the regressions variables, so that the error terms of the probit regressions regarding OBESITY, SEVERE OBESITY, and UNDERWEIGHT, conducted independently in Sections 4.2 and 4.3, may well be correlated with each other. Based on the assumption that the error terms are correlated with each other, the probabilities of being obese, severely obese, and underweight can be jointly estimated by conducting multivariate probit regression. The results are reported in Table A6. It can be seen that the results regarding the signs and the significance levels of the estimated coefficients do not differ largely from those in Tables 11-13. Note that significant correlations among the error terms remain.

\footnotetext{
${ }^{27}$ For example, among 1658 samples in Table 12 that are used to estimate Model (1) in the SEVERE OBESITY regression, the number of the severely obese respondents is less than 50, whereas the number of the prefecture and occupation dummies amounts to 58 .
} 
Insert Table A5:

Multivariate probit estimation of the prob. of being obesity, severely obese, and underweight

\section{Using the uncorrected body mass data}

We finally report the estimation results when the uncorrected data of BMI, OBESITY, and SEVERE OBESITY, instead of the corrected data, are used to estimate the same models as estimated in Tables 9, 11, and 12 (note that the data of UNDERWEIGHT are not revised from the original data).

Insert Table A6:

OLS regressions of uncorrected BMI

Insert Table A7:

Binary probit regressions of obesity by the uncorrected data

Insert Table A8:

Binary probit regressions of severe obesity by the uncorrected data 


\section{References}

[1] Ainslie, G., 2001, Breakdown of Will, Cambridge, UK: Cambridge University Press.

[2] Becker, G.S. and K.M. Murphy, 1988, A theory of rational addiction, Journal of Political Economy 96, 675-700.

[3] Benzion, U., A. Rapoport, and J. Yagil, 1989, Discount rates inferred from decisions: An experimental study, Management Science 35, 270284.

[4] Borghans, L., and Golsteyn, B, H.H., 2006, Time discounting and the body mass index: Evidence from the Netherlands, Economics and $\mathrm{Hu}-$ man Biology 4, 39-61.

[5] Cawley, J., 2004, The impact of obesity on wages, Journal of Human Resources 39, 452-474.

[6] Cawley, J. and R.V. Burkhauser, 2006, Beyond BMI: The value of more accurate measures of fatness and obesity in social science research, NBER Discussion Paper 12291.

[7] Chapman, G.E., 1995, Valuing the future, temporal discounting of health and money, Medical Decision Making 15, 373-386.

[8] Chou, S., M. Grossman, and H. Saffer, 2004, An economic analysis of adult obesity: results from the Behavioral Risk Factor Surveillance System, Journal of Health Economics 23, 565-587.

[9] Cutler, D.M. and E.L. Glaeser, 2005, What explains differences in smoking, drinking, and other health-related behaviors?, American Economic Review 95, Papers and Proceedings, 238-242.

[10] Cutler, D.M., E.L. Glaeser, and J.M. Shapiro, 2003, Why have Americans become more obese? Journal of Economic Perspective 17, 93-118.

[11] The Examination Committee of Criteria for 'Obesity Disease' in Japan, chaired by Y. Matsuzawa, Japan Society for the Study of Obesity, 2002, New criteria for 'obesity disease' in Japan, Circulation Journal 66, 987992.

[12] Frederick, S.G., G. Loewenstein, and T. O 'Donoghue, 2002, Time discounting and time preference: A critical review, Journal of Economic Literature 40, 351-401. 
[13] Harrison, G.W., M.I. Lau, and M.B. Williams, 2002, Estimating individual discount rates in Denmark: A field experiment, American Economic Review 92, 1606-1617.

[14] Khwaja, A., D. Silverman, and F. Sloan, 2007, Time preference, time discounting, and smoking decisions, Journal of Health Economics 26, 927-949.

[15] Komlos, J., P.K. Smith, and B. Bogin, 2004, Obesity and the rate of time preference: Is there a connection?, Journal of Biosocial Science, 36, 209-219.

[16] Laibson, D., 1997, Golden Eggs and Hyperbolic Discounting, Quarterly Journal of Economics, 112, 443-477.

[17] Laibson, D., 1998, Life-Cycle Consumption and Hyperbolic Discount Functions, European Economic Review 42, 861-871.

[18] Loewenstein, G., 1987, Anticipation and the Valuation of delayed consumption, Economic Journal XLVII, 666-687.

[19] Loewenstein, G., and Prelec, D, 1992, Anomalies Intertemporal Choice: Evidence and an Interpretation, Quarterly Journal of Economics, 107, 573-597.

[20] Michaud, P-C., van Soest, A.H.O., and T. Andreyeva, 2007, Crosscountry variation in obesity patters among older Americans and Europeans, Forum for Health Economics \& Policy 10, Article 8. 1-30.

[21] Ohtake, F., 2005, The sense of economic thinking, Chuo-Koron-Shinsha (in Japanese).

[22] Philipson, T., 2001,The world-wide growth in obesity: An economic research agenda, Health Economics 10, 1-7.

[23] Smith, P. K., Bogin, B., and Bishai, D., 2005, Are time preference and body mass index associated ?, Economics and Human Biology 3, 259270.

[24] Suzuki, W., 2007, Obesity and overworking, presented at the fall meeting of JEA, held at Tohoku University, Japan (in Japanese).

[25] Thaler, R., 1981, Some empirical evidence on dynamic inconsistency, Economics Letters 8, 201-207. 
Table 1: Debt holdings and body mass

\begin{tabular}{|c|c|c|c|c|}
\hline & \multicolumn{4}{|c|}{ All } \\
\hline & BMI & Obesity & $\begin{array}{c}\text { Severe } \\
\text { Obesity }\end{array}$ & Underweight \\
\hline \multirow{5}{*}{$\begin{array}{l}\text { Debtors } \\
\text { Nondebtors } \\
\text { (t-values) }\end{array}$} & 23.262 & 0.287 & 0.045 & 0.060 \\
\hline & 22.714 & 0.227 & 0.027 & 0.074 \\
\hline & $(3.671)^{* * *}$ & $(3.153)^{* * *}$ & $(2.348) * *$ & $(-1.240)$ \\
\hline & \multicolumn{4}{|c|}{ Male } \\
\hline & BMI & Obesity & $\begin{array}{l}\text { Severe } \\
\text { Obesity }\end{array}$ & Underweight \\
\hline \multirow{5}{*}{$\begin{array}{l}\text { Debtors } \\
\text { Nondebtors } \\
\text { (t-values) }\end{array}$} & 23.898 & 0.345 & 0.044 & 0.027 \\
\hline & 23.506 & 0.278 & 0.035 & 0.043 \\
\hline & $(1.880) *$ & $(2.322)^{* *}$ & $(0.814)$ & $(-1.341)$ \\
\hline & \multicolumn{4}{|c|}{ Female } \\
\hline & BMI & Obesity & $\begin{array}{l}\text { Severe } \\
\text { Obesity }\end{array}$ & Underweight \\
\hline Debtors & 22.635 & 0.230 & 0.047 & 0.093 \\
\hline Nondebtors & 22.005 & 0.182 & 0.021 & 0.102 \\
\hline (t-values) & $(3.084) * * *$ & $(1.962)^{* *}$ & $(2.587)^{* * *}$ & $(-0.481)$ \\
\hline
\end{tabular}

Notes: The data are those from the Japan Household Survey on Consumer Preferences and Satisfaction 2005, corrected for the self-reporting biases. For the correction method, see Section 3.1.

The t-values represent those for mean differences in body mass statuses between debtors and nondebtors. *, **,*** denote statistical significance at the $10 \%, 5 \%$, and $1 \%$ levels, respectively. 
Table 2: Definitions of obesity and underweight

\begin{tabular}{|c|c|c|c|}
\hline BMI & WHO criteria & JSSO criteria & This paper \\
\hline $\mathrm{BMI}<18.5$ & Unnderweight & Underweight & Underweight \\
$18.5 \leqq \mathrm{BMI}<25$ & Normal range & Normal range & Normal range \\
$\mathrm{BMI}=22$ & Standard (ideal) & Standard (ideal) & Standard (ideal) \\
\cline { 4 - 4 } $25 \leqq \mathrm{BMI}<30$ & Preobese & Obese (degree1) & Obese \\
$30 \leqq \mathrm{BMI}<35$ & Obese (class I) & Obese (degree2) & \\
$35 \leqq \mathrm{BMI}<40$ & Obese (class II) & Obese (degree3) & Severe-Obese \\
$40 \leqq \mathrm{BMI}$ & Obese (class III) & Obese (degree3) & \\
\hline
\end{tabular}

N ote: The J SSO criteria are based on "N ew Criteria," 2002, J apan Society for the Study of Obesity. 
Table 3(a): By-age BMI distributions: NSHN04, JHS05, and corrected data.

\begin{tabular}{|c|c|c|c|c|c|c|c|c|c|c|c|}
\hline \multirow[b]{2}{*}{ Age } & & \multicolumn{5}{|c|}{ Male } & \multicolumn{5}{|c|}{ Female } \\
\hline & & NSHN04 & & JHS05 & Corre & ccted data & NSHN04 & & JHS05 & Cor & rected data \\
\hline \multirow{2}{*}{$20 \mathrm{~s}$} & Means & 22.52 & 22.46 & $(0.448)$ & 22.66 & $(0.623)$ & 20.28 & 20.23 & $(0.428)$ & 20.29 & $(0.572)$ \\
\hline & S.D. & 3.62 & 3.98 & $(0.107)$ & 4.09 & $(0.054)^{*}$ & 2.54 & 2.55 & $(0.474)$ & 2.64 & $(0.281)$ \\
\hline \multirow{2}{*}{$30 \mathrm{~s}$} & Means & 23.42 & 23.25 & $(0.284)$ & 23.38 & $(0.451)$ & 20.95 & 20.84 & $(0.302)$ & 20.85 & $(0.699)$ \\
\hline & S.D. & 3.36 & 3.61 & $(0.111)$ & 3.69 & $(0.060) *$ & 2.99 & 2.62 & $(0.008)^{* * *}$ & 2.62 & $(0.008)^{* * *}$ \\
\hline \multirow{2}{*}{$40 \mathrm{~s}$} & Means & 24.07 & 23.63 & $(0.045)^{*}$ & 23.85 & $(0.202)$ & 22.64 & 22.03 & $(0.004)^{* * *}$ & 22.19 & $(0.996)^{*}$ \\
\hline & S.D. & 3.37 & 3.30 & $(0.353)$ & 3.40 & $(0.432)$ & 3.57 & 2.98 & $(0.000)^{* * *}$ & 3.12 & $(0.004)^{* * *}$ \\
\hline \multirow{2}{*}{$50 \mathrm{~s}$} & Means & 23.69 & 23.57 & $(0.262)$ & 23.76 & $(0.640)$ & 22.97 & 22.36 & $(0.001)^{* * *}$ & 22.71 & $(0.999)$ \\
\hline & S.D. & 2.89 & 2.92 & $(0.399)$ & 3.02 & (0.169) & 3.21 & 2.80 & $(0.001)^{* * *}$ & 3.21 & $(0.492)$ \\
\hline \multirow{2}{*}{$60-71$} & Means & 23.75 & 23.24 & $(0.002)$ & 23.61 & $(0.2$ & 23.35 & 22.87 & $(0.010)^{* *}$ & 23.29 & $(0.990)$ \\
\hline & S.D. & 3.00 & 2.60 & $(0.001)^{* * *}$ & 2.99 & $(0.478)$ & 3.47 & 3.01 & $(0.001)^{* * *}$ & 3.57 & $(0.273)$ \\
\hline \multirow{3}{*}{ all } & Means & 23.65 & 23.35 & $(0.003)^{* * *}$ & 23.59 & $(0.298)$ & 22.37 & 21.94 & $(0.000)^{* * *}$ & 22.17 & $(1.000)^{*}$ \\
\hline & S.D. & 3.15 & 3.14 & $(0.457)$ & 3.31 & $(0.022)^{* *}$ & 3.25 & 2.96 & $(0.000)^{* * *}$ & 3.29 & $(0.291)$ \\
\hline & Obs. & 2286 & & 1368 & & 1368 & 2789 & & 1499 & & 1499 \\
\hline
\end{tabular}

Notes: Values in parentheses represent P-values for the null hypotheses that coresponding statistics equal those of the NSHN04 data. $*, * *, * * *$ denote statistical significance at the $10 \%, 5 \%$, and $1 \%$ levels, respectively. 
Table 3(b): By-age obesity distributions: NSHN04, JHS05, and corrected data.

\begin{tabular}{|c|c|c|c|c|c|c|}
\hline & \multicolumn{3}{|c|}{ Male } & \multicolumn{3}{|c|}{ Female } \\
\hline & NSHN04 & JHS05 & Corrected data & NSHN04 & JHS05 & Corrected data \\
\hline $20 \mathrm{~s}$ & 0.199 & $0.133(0.025)^{* *}$ & $0.195(0.876)$ & 0.054 & $0.035(0.261)$ & $0.049(0.915)$ \\
\hline $30 \mathrm{~s}$ & 0.289 & $0.252(0.167)$ & $0.292(0.922)$ & 0.083 & $0.079(0.745)$ & $0.086(0.782)$ \\
\hline $40 \mathrm{~s}$ & 0.327 & $0.267(0.012)^{* *}$ & $0.324(0.885)$ & 0.179 & $0.139(0.016)^{* *}$ & $0.179(0.976)$ \\
\hline $50 \mathrm{~s}$ & 0.308 & $0.248(0.003)^{* * *}$ & $0.305(0.918)$ & 0.241 & $0.161(0.000)^{* * *}$ & $0.240(0.955)$ \\
\hline $60-71$ & 0.299 & $0.237(0.002)^{* * *}$ & $0.298(0.984)$ & 0.298 & $0.218(0.000)^{* * *}$ & $0.297(0.964)$ \\
\hline all & 0.297 & $0.240(0.000)^{* * *}$ & $0.296(0.893)$ & 0.195 & $0.143(0.000)^{* * *}$ & $0.195(0.956)$ \\
\hline Obs. & 2286 & 1368 & 1368 & 2789 & 1499 & 1499 \\
\hline
\end{tabular}

Notes: Values in parentheses represent P-values for the null hypotheses that coresponding statistics equal those of the NSHN04 data. *, **, *** denote statistical significance at the $10 \%, 5 \%$, and $1 \%$ levels, respectively.

Table 3(c): By-age severe obesity distributions: NSHN04, JHS05, and corrected data.

\begin{tabular}{|c|c|c|c|c|c|c|}
\hline & \multicolumn{3}{|c|}{ Male } & \multicolumn{3}{|c|}{ Female } \\
\hline & NSHN04 & JHS05 & Corrected data & NSHN04 & JHS05 & Corrected data \\
\hline $20 \mathrm{~s}$ & 0.021 & $0.035(0.290)$ & $0.035(0.290)$ & 0.008 & $0.007 \quad(0.655)$ & $0.007 \quad(0.655)$ \\
\hline $30 \mathrm{~s}$ & 0.030 & $0.050(0.052) *$ & $0.050(0.052)^{* *}$ & 0.012 & $0.008(0.523)$ & $0.008(0.523)$ \\
\hline $40 s$ & 0.034 & $0.036(0.960)$ & $0.036(0.960)$ & 0.027 & $0.015(0.106)$ & $0.024(0.848)$ \\
\hline $50 \mathrm{~s}$ & 0.032 & $0.034(0.779)$ & $0.034(0.780)$ & 0.036 & $0.015(0.001)^{* * *}$ & $0.032(0.541)$ \\
\hline $60-71$ & 0.031 & $0.008(0.000)^{* * *}$ & $0.031(0.956)$ & 0.045 & $0.025(0.013)^{* *}$ & $0.048 \quad(0.724)$ \\
\hline all & 0.031 & $0.029(0.586)$ & $0.036(0.159)$ & 0.029 & $0.015(0.000)^{* * *}$ & $0.027(0.516)$ \\
\hline Obs. & 2286 & 1368 & 1368 & 2789 & 1499 & 1499 \\
\hline
\end{tabular}

Notes: Values in parentheses represent P-values for the null hypotheses that coresponding statistics equal those of the NSHN04 data. *, **, *** denote statistical significance at the $10 \%, 5 \%$, and $1 \%$ levels, respectively.

Table 3(d): By-age underweight distributions: NSHN04, JHS05, and corrected data.

\begin{tabular}{cccc|rcc}
\multicolumn{3}{c|}{ Male } & \multicolumn{3}{c}{ Female } \\
\hline NSHN04 & JHS05 (Corrected) & NSHN04 & JHS05 (Corrected) \\
\hline 20s & 0.084 & $0.115(0.114)$ & 0.214 & $0.211(0.913)$ \\
\hline 30s & 0.038 & $0.074(0.000)^{* * *}$ & 0.156 & $0.143(0.431)$ \\
\hline $50 \mathrm{~s}$ & 0.021 & $0.032(0.112)$ & 0.066 & $0.103(0.000)^{* * *}$ \\
\hline $60-71$ & 0.036 & $0.036(0.994)$ & 0.066 & $0.050(0.105)$ \\
\hline all & 0.033 & $0.042(0.010)^{* *}$ & 0.093 & $0.095(0.625)$ \\
\hline Obs. & 2286 & & 1368 & 2789 & 1499
\end{tabular}

Notes: Values in parentheses represent P-values for the null hypotheses that coresponding statistics equal those of the NSHN04 data. *, **, *** denote statistical significance at the $10 \%, 5 \%$, and $1 \%$ levels, respectively. 
Table 4: Question to elicit discount rates: An example (QUESTION 1 for $\mathrm{DR}_{\mathbf{1}}$ )

\section{QUESTION 1.}

Suppose you have two options to receive some money. You may choose Option "A", to receive 10,000 JPY in two days; or Option "B", to receive a different amount in nine days. Compare the amounts and timing in Option "A" with Option "B" and indicate which amount you would prefer to receive for each of all 8 choices.

\begin{tabular}{|r|r|r|r|c|}
\hline $\begin{array}{c}\text { Option A (JPY) } \\
\text { (Receipt in 2 days) }\end{array}$ & $\begin{array}{c}\text { Option B (JPY) } \\
\text { (Receipt in 9 days) }\end{array}$ & $\begin{array}{c}\text { Interest rate } \\
\text { (Annual) }\end{array}$ & \multicolumn{2}{|c|}{ Circle A or B. } \\
\hline \hline 10,000 & 9,981 & $-10 \%$ & A & B \\
\hline 10,000 & 10,000 & $0 \%$ & A & B \\
\hline 10,000 & 10,019 & $10 \%$ & A & B \\
\hline 10,000 & 10,038 & $20 \%$ & A & B \\
\hline 10,000 & 10,096 & $50 \%$ & A & B \\
\hline 10,000 & 10,191 & $100 \%$ & A & B \\
\hline 10,000 & 10,383 & $200 \%$ & A & B \\
\hline 10,000 & 10,574 & $300 \%$ & A & B \\
\hline
\end{tabular}

Note: The Japan Household Survey on Consumer Preferences and Satisfaction, 2005. 
Table 5: Elicited discount rates under alternative choice conditions

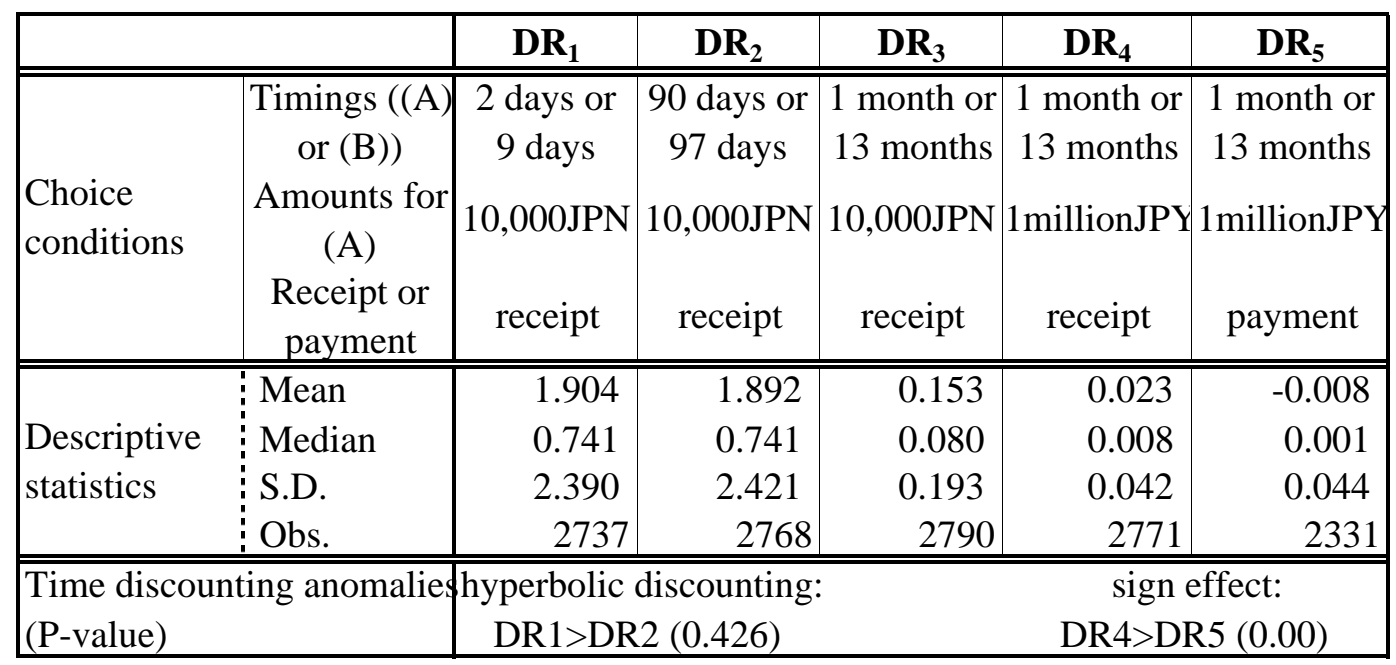

Note: The Japan Household Survey on Consumer Preferences and Satisfaction, 2005. 
Table 6: Definitions of variables and basic statistics

\begin{tabular}{|c|c|c|c|c|}
\hline Variables & Definition & Mean & S.D. & Obs. \\
\hline BMI & $\begin{array}{l}\text { Body mass index data that are corrected for the self-reporting bias by using the manners } \\
\text { explained in Section } 3.1\end{array}$ & 22.846 & 3.371 & 2869 \\
\hline OBESITY & A binary indicator for obesity which equals 1 if BMI $\geqq 25$ and 0 otherwise & 0.243 & 0.429 & 2869 \\
\hline SEVERE OBESITY & A binary indicator for severe obesity which equals 1 if BMI $\geqq 30$ and 0 otherwise & 0.031 & 0.174 & 2869 \\
\hline UNDERWEIGHT & A binary indicator for underweight which equals 1 if $\mathrm{BMI}<18.5$ and 0 otherwise & 0.070 & 0.255 & 2869 \\
\hline DRSTD & $\begin{array}{l}\text { Simple mean, defined by equation (1), of the standardized values of the elicited discount } \\
\text { rates } \mathrm{DR}_{i}(i=1, \ldots, 5) \text { as a measure of the degree of impatience }\end{array}$ & 0.042 & 0.688 & 2202 \\
\hline DEBTIMP & $\begin{array}{l}\text { A proxy of the degree of impatience, measured by standardized residuals of debt holding } \\
\text { DEBT after regressing it on explanatory variables other than the degree of impatience } \\
\text { (see the first regression in Table 5) }\end{array}$ & 0.000 & 1.000 & 1704 \\
\hline HYPERBOL & $\begin{array}{l}\text { A binary indicator for hyperbolic discounting which equals } 1 \text { if } \mathrm{DR}_{1}>\mathrm{DR}_{2} \text {, and } 0 \\
\text { otherwise. }\end{array}$ & 0.621 & 0.485 & 2694 \\
\hline PROCR & $\begin{array}{l}\text { Response to the question 'When did you do homework assignments in the summer } \\
\text { vacation in your high school days?' on a 5-point scale, from } 1 \text { (homework was finished at } \\
\text { 'the beginning of the vacation') to } 5 \text { (it was not done until 'the very end of the vacation'), } \\
\text { which is a proxy measure of the degree of procrastination. }\end{array}$ & 3.282 & 1.300 & 2910 \\
\hline SIGN & A binary indicator for the sign effect which equals 1 if $\mathrm{DR}_{4}>\mathrm{DR}_{5}$, and 0 otherwise & 0.885 & 0.319 & 2289 \\
\hline RISKAV & $\begin{array}{l}\text { A variable which measures the degree of risk aversion, constructed by subtracting from } \\
100 \text { the respondents' responses to the question: "When you go out, how high probability } \\
\text { of rainfall makes you bring an umbrella with you?" }\end{array}$ & 0.505 & 0.205 & 2941 \\
\hline MALE & A binary indicator for males which equals 1 for male respondents and 0 otherwise & 0.470 & 0.499 & 2987 \\
\hline UNIV & $\begin{array}{l}\text { A binary indicator for university graduates which equals } 1 \text { for university graduates and } 0 \\
\text { otherwise }\end{array}$ & 0.204 & 0.403 & 2893 \\
\hline AGE & Ages of respondents & 49.080 & 12.968 & 2983 \\
\hline DEBT & $\begin{array}{l}\text { A binary indicator for debt holding other than housing loan which equals } 1 \text { for debt } \\
\text { holders and } 0 \text { otherwise. }\end{array}$ & 0.251 & 0.434 & 2806 \\
\hline INCOME & Per capita household income in million yen & 2.213 & 1.583 & 2361 \\
\hline$\Delta$ INCOME & $\begin{array}{l}\text { The expected percentage change of income in a forthcoming year, estimated from } \\
\text { responses to the question: 'What is the expected rate of change in your whole household } \\
\text { income this year?' }\end{array}$ & -0.948 & 3.914 & 2707 \\
\hline WORKHOUR & Work hours for a week & 27.191 & 22.922 & 2879 \\
\hline SMOKING & $\begin{array}{l}\text { A ordered variable indicating the strength of smoking habits on a 6-point scale, from } 1 \\
\text { (smoking no cigarette a day) to } 6 \text { (smoking more than two packages of cigarettes a day) }\end{array}$ & 2.125 & 1.713 & 2972 \\
\hline
\end{tabular}


Table 7: Time discounting and debt holdings

\begin{tabular}{|c|c|c|}
\hline $\begin{array}{l}\text { Dependent } \\
\text { variable: DEBT }\end{array}$ & Marginal Effects ( $t$-value) & Marginal Effects ( $t$-value) \\
\hline DRSTD & & $(5.434)^{* * *}$ \\
\hline PROCR & $(1.819)^{*}$ & $(1.617)$ \\
\hline SIGN & $-0.057 \quad(-1.724)^{*}$ & $-0.066 \quad(-1.892)^{*}$ \\
\hline RISKAV & $-0.174 \quad(-3.342)^{* * *}$ & $-0.174 \quad(-3.228)^{* * *}$ \\
\hline UNIV & $-0.054 \quad(-2.141)^{* *}$ & $-0.062 \quad(-2.429)^{* *}$ \\
\hline AGE & $0.021 \quad(3.315)^{* * *}$ & $0.021 \quad(3.227)^{* * *}$ \\
\hline $\mathrm{AGE}^{\wedge} 2$ & $0.000 \quad(-4.000)^{* * *}$ & $0.000 \quad(-3.935)^{* * *}$ \\
\hline INCOME & $-0.036 \quad(-2.168)^{* *}$ & $-0.043(-2.441)^{* *}$ \\
\hline $\mathrm{INCOME}^{\wedge} 2$ & $0.004 \quad(2.337)^{* *}$ & $0.006 \quad(2.708)^{* * *}$ \\
\hline$\triangle \mathrm{INCOME}$ & $-0.006 \quad(-2.099)^{* *}$ & $-0.007 \quad(-2.440)^{* *}$ \\
\hline Log likelihood & -928.902 & -875.692 \\
\hline \#obs & 1704 & 1640 \\
\hline
\end{tabular}

Notes: The probabiltiy of debt holding is estimated by using binary probit models. $*, * *, * * *$ denote statistical significance at the $10 \%, 5 \%$, and $1 \%$ levels, respectively.

Table 8: Correlations between impatience proxy (DEBTIMP) and elicited discount rates.

\begin{tabular}{|l|cccccc|}
\hline & DRSTD & $\mathrm{DR}_{1}$ & $\mathrm{DR}_{2}$ & $\mathrm{DR}_{3}$ & $\mathrm{DR}_{4}$ & $\mathrm{DR}_{5}$ \\
\hline DEBTIMP & 0.137 & 0.091 & 0.071 & 0.115 & 0.110 & 0.080 \\
$(t$-values $)$ & $(5.583)^{* * *}$ & $(3.711)^{* * *}$ & $(2.919)^{* * *}$ & $(4.762)^{* * *}$ & $(4.555)^{* * *}$ & $(3.325)^{* * *}$ \\
\hline
\end{tabular}

Notes: Impatience proxy DEBTIMP is construcetd from standardized residuals of the binary probit estimation of the probability of debt holding (see the first result in Table 7). *** denotes statistical significance at the $1 \%$ level. 
Table 9: OLS regressions of BMI

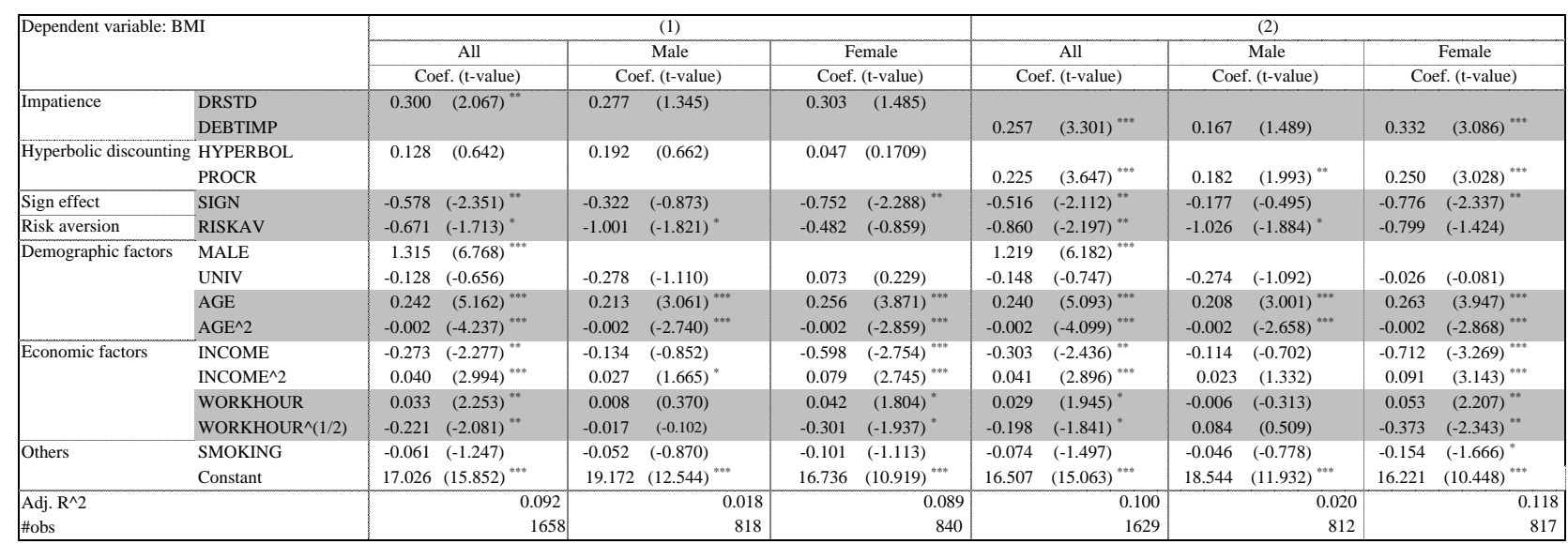

Notes: $*, * *, * * *$ denote statistical significance at the $10 \%, 5 \%$, and $1 \%$ levels, respectively. 


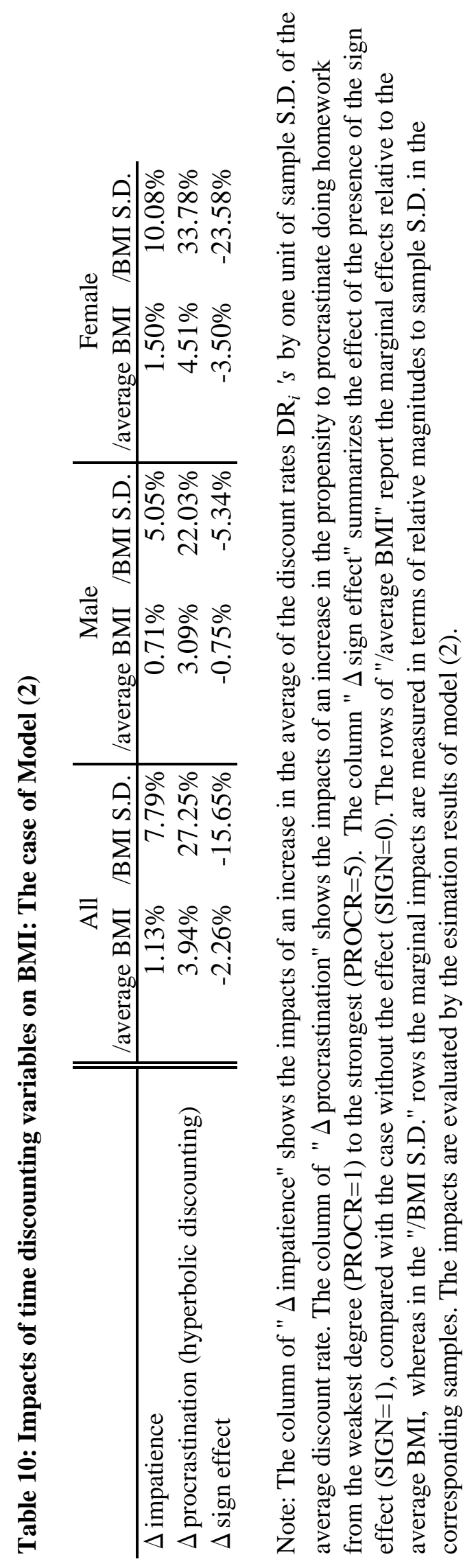


Table 11: Binary probit regressions of obesity

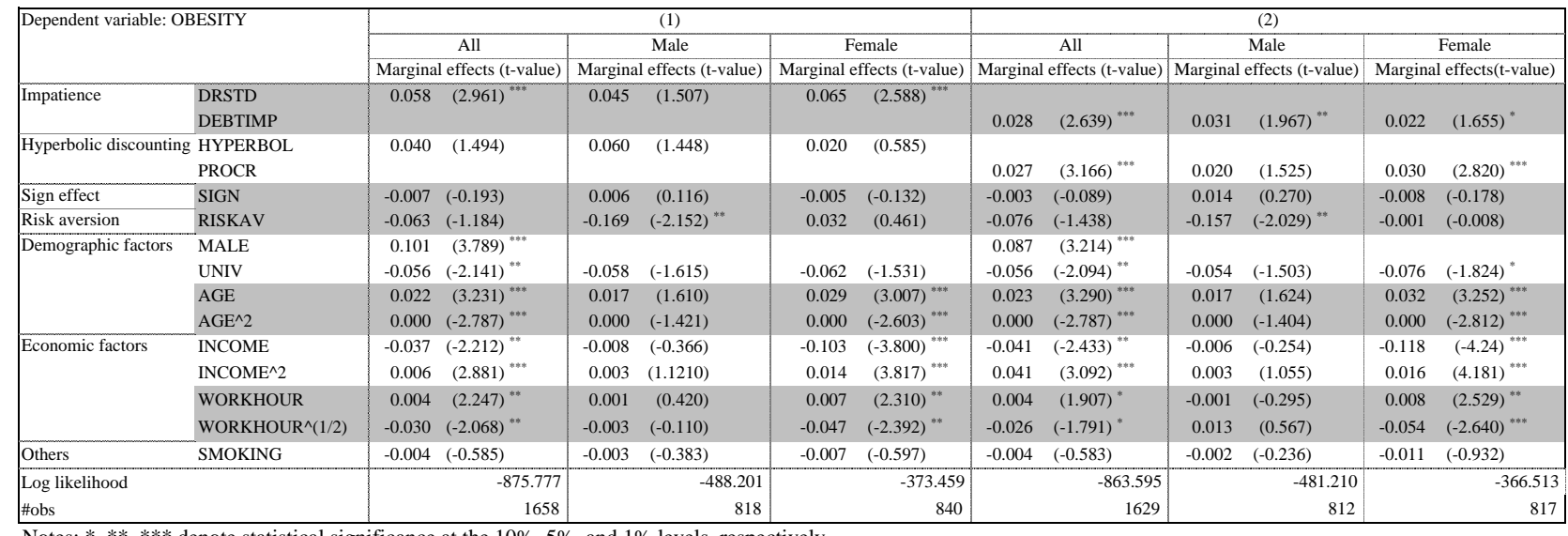

Notes: ${ }^{*}, * *, * * *$ denote statistical significance at the $10 \%, 5 \%$, and $1 \%$ levels, respectively.

Table 12: Binary probit regressions of severe obesity

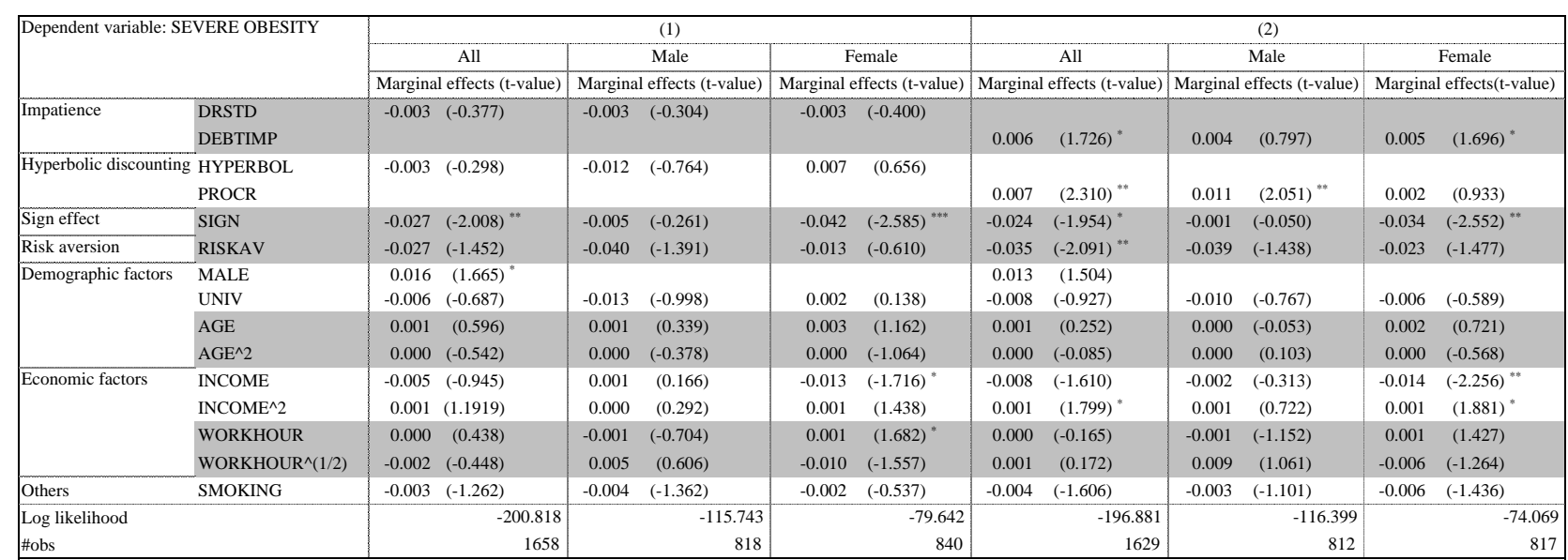

Notes: ${ }^{*}, * *, * * *$ denote statistical significance at the $10 \%, 5 \%$, and $1 \%$ levels, respectively.

Table 13: Binary probit regressions of underweight

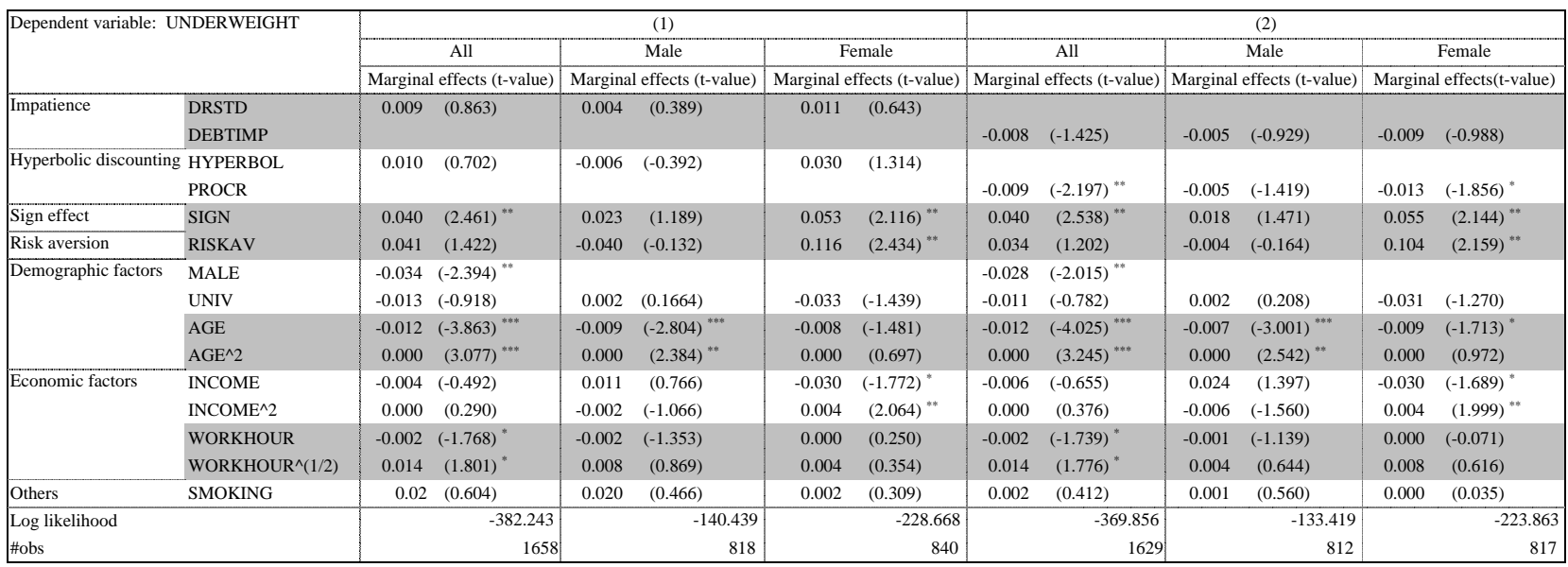

Notes: $*, * *, * * *$ denote statistical significance at the $10 \%, 5 \%$, and $1 \%$ levels, respectively. 


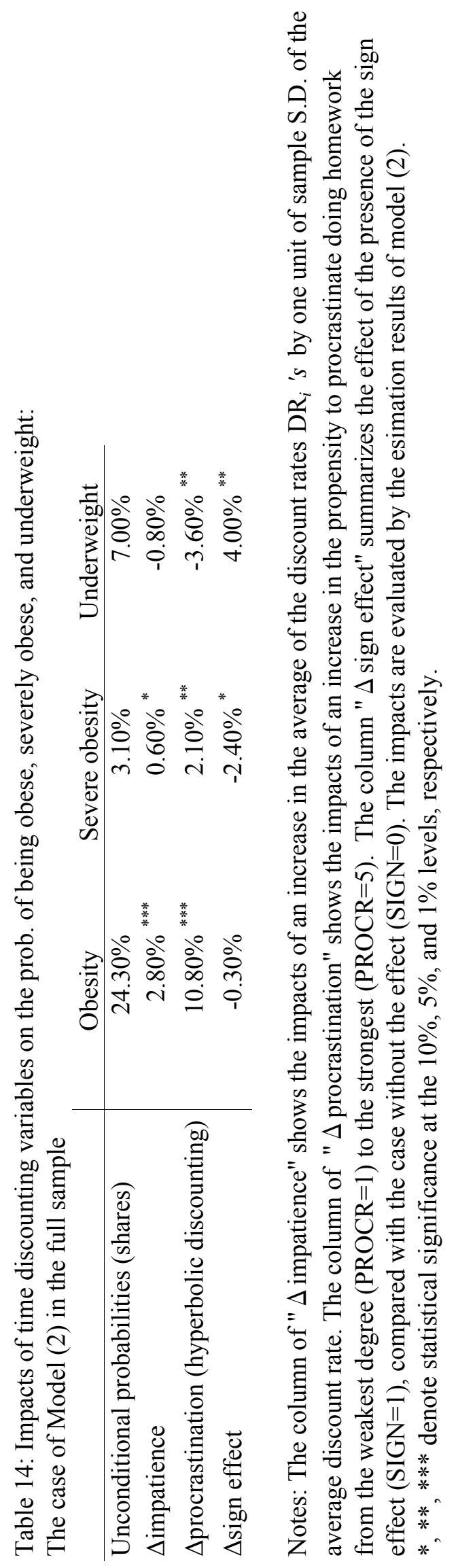


Table A1: OLS regression of BMI with prefecture and occupation dummies

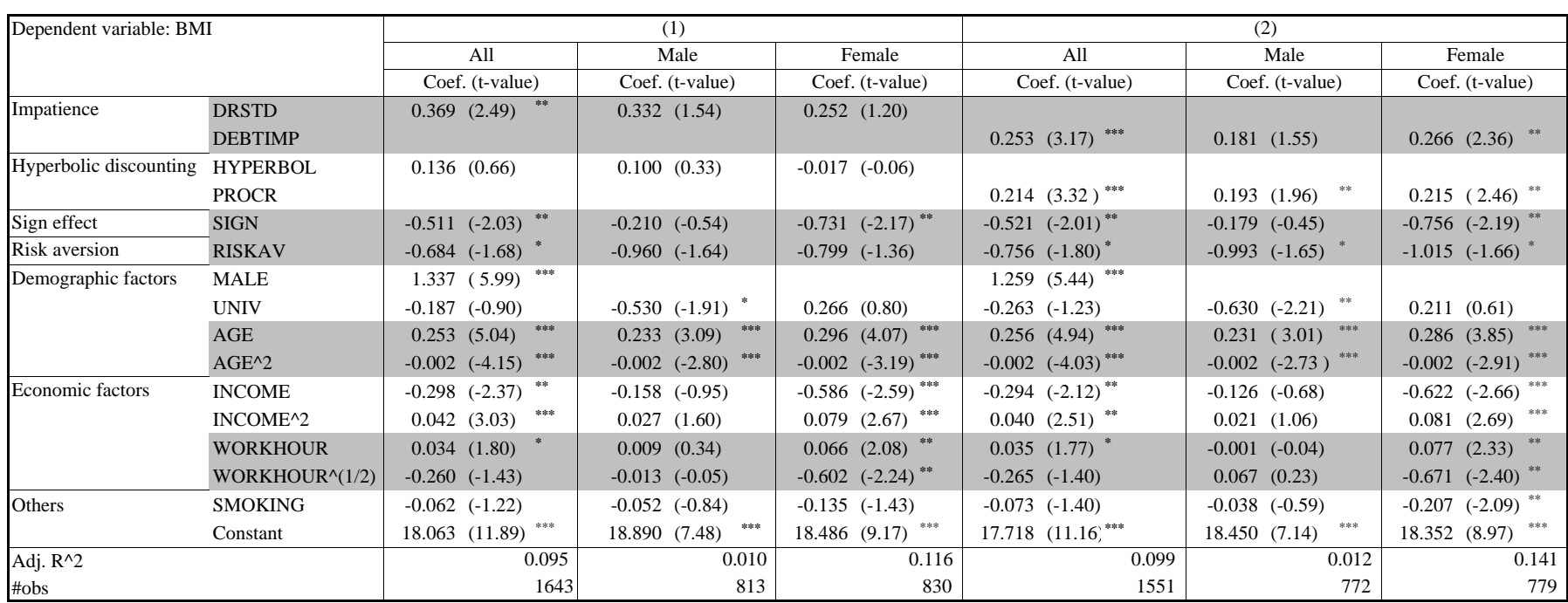

Notes: $*, * *, * * *$ denote statistical significance at the $10 \%, 5 \%$, and $1 \%$ levels, respectively.

The prefecture dummies (47) and the occupation dummies (12) are added to the set of explanatory variables.

The estimated coefficients of those dummies are not reported in the table. 
Table A2: Binary probit regression of obesity with prefecture and occupation dummies

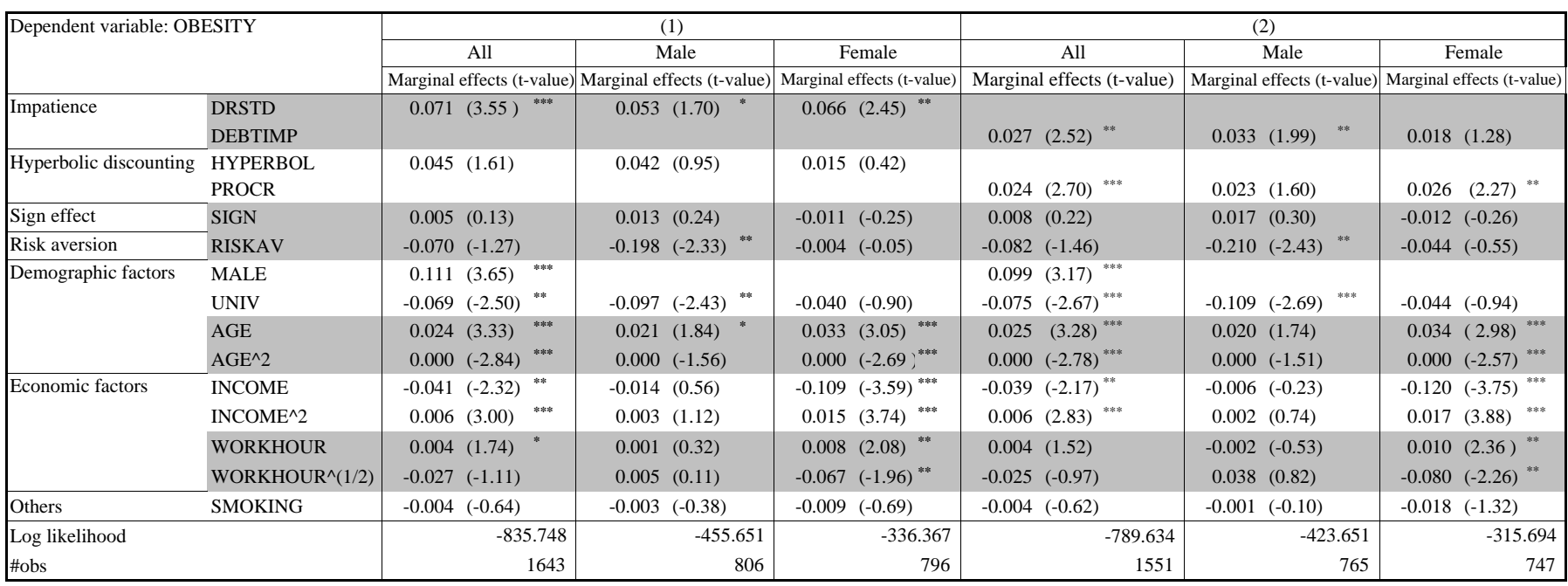

Notes: $*, * *, * * *$ denote statistical significance at the $10 \%, 5 \%$, and $1 \%$ levels, respectively.

The prefecture dummies (47) and the occupation dummies (12) are added to the set of explanatory variables.

The estimated coefficients of those dummies are not reported in the table.

Table A3: Binary probit regression of severe obesity with prefecture and occupation dummies

\begin{tabular}{|c|c|c|c|c|c|c|c|c|}
\hline & \multicolumn{3}{|c|}{ (1) } & \multicolumn{4}{|c|}{ (2) } \\
\hline \multirow{2}{*}{\multicolumn{2}{|c|}{ Dependent variable: SEVERE OBESITY }} & All & Male & Female & All & \multicolumn{2}{|r|}{ Male } & Female \\
\hline & & Marginal effects (t-value) & Marginal effects (t-value) & Marginal effects (t-value) & Marginal effects (t-value) & Marginal & effects (t-value) & Marginal effects (t-value) \\
\hline Impatience & $\begin{array}{l}\text { DRSTD } \\
\text { DEBTIMP }\end{array}$ & $-0.001(-0.16)$ & $-0.002(-0.09)$ & $-0.005(-0.48)$ & $0.007(1.93){ }^{*}$ & 0.008 & $(0.87)$ & $0.005(2.18)$ ** \\
\hline Hyperbolic discounting & $\begin{array}{l}\text { HYPERBOL } \\
\text { PROCR }\end{array}$ & $-0.002(-0.20)$ & $-0.021 \quad(-0.81)$ & $0.010(0.71)$ & $0.009(2.58)^{* * *}$ & 0.019 & $(2.18)^{* *}$ & $0.002(1.34)$ \\
\hline Sign effect & SIGN & $-0.025(-1.60)$ & $0.004(0.15)$ & $-0.041(-1.76)$ & $-0.026(-1.81)^{*}$ & 0.007 & $(0.25)$ & $-0.027(-1.79){ }^{*}$ \\
\hline Risk aversion & RISKAV & $-0.027(-1.21)$ & $-0.056(-1.15)$ & $-0.023 \quad(-0.77)$ & $-0.023(-1.20)$ & -0.045 & $(-0.98)$ & $-0.013(-0.95)$ \\
\hline Demographic factors & $\begin{array}{l}\text { MALE } \\
\text { UNIV }\end{array}$ & $\begin{aligned} 0.016 & (1.31) \\
-0.005 & (-0.43)\end{aligned}$ & $-0.012(-0.55)$ & $0.014(0.72)$ & $\begin{array}{rr}0.012 & (1.12) \\
-0.006 & (-0.66)\end{array}$ & -0.008 & $(0.701)$ & $-0.002(-0.36)$ \\
\hline & $\begin{array}{l}\mathrm{AGE} \\
\mathrm{AGE} \wedge 2\end{array}$ & $\begin{array}{ll}0.003 & (1.00) \\
0.000 & (-1.02)\end{array}$ & $\begin{array}{ll}0.007 & (1.07) \\
0.000 & (-1.10)\end{array}$ & $\begin{array}{ll}0.004 & (1.00) \\
0.000 & (-0.95)\end{array}$ & $\begin{array}{ll}0.002 & (0.90) \\
0.000 & (-0.82)\end{array}$ & $\begin{array}{l}0.005 \\
0.000\end{array}$ & $\begin{array}{l}(0.83) \\
(-0.80)\end{array}$ & $\begin{array}{ll}0.000 & (0.13) \\
0.000 & (0.01)\end{array}$ \\
\hline Economic factors & $\begin{array}{l}\text { INCOME } \\
\text { INCOME^2 }\end{array}$ & $\begin{array}{cl}-0.006 & (-1.00) \\
0.001 & (1.47)\end{array}$ & $\begin{array}{ll}0.001 & (0.09) \\
0.001 & (0.60)\end{array}$ & $\begin{array}{cl}-0.017 & (-1.59) \\
0.002 & (1.46)\end{array}$ & $\begin{array}{cl}-0.006 & (-1.15) \\
0.001 & (1.56)\end{array}$ & $\begin{array}{l}0.000 \\
0.001\end{array}$ & $\begin{array}{l}(-0.01) \\
(0.59)\end{array}$ & $\begin{array}{r}-0.011(-2.30) \\
0.001 \quad(2.07)\end{array}{ }^{* *}$ \\
\hline & $\begin{array}{l}\text { WORKHOUR } \\
\text { WORKHOUR^(1/2) }\end{array}$ & $\begin{aligned} 0.000 & (0.46) \\
-0.006 & (-0.67)\end{aligned}$ & $\begin{aligned}-0.002 & (-0.54) \\
0.011 & (0.34)\end{aligned}$ & $\begin{array}{rr}0.002 & (1.69) \\
-0.020 & (-1.82)^{*}\end{array}$ & $\begin{array}{cc}0.001 & (0.67) \\
-0.008 & (-0.90)\end{array}$ & $\begin{array}{c}-0.002 \\
0.014\end{array}$ & $\begin{array}{l}(-0.63) \\
(0.41)\end{array}$ & $\begin{array}{r}0.001(1.96) \\
-0.010 \quad(-1.98)\end{array}$ *** \\
\hline Others & SMOKING & $-0.004(-1.65)^{*}$ & $-0.009(-1.76)^{*}$ & $-0.002(-0.54)$ & $-0.005(-2.18)^{* * *}$ & -0.009 & $(-1.72)^{*}$ & $-0.006(-1.67){ }^{*}$ \\
\hline $\begin{array}{l}\text { Log likelihood } \\
\text { \#obs }\end{array}$ & & $\begin{array}{r}-171.938 \\
1192\end{array}$ & $\begin{array}{r}-91.510 \\
444\end{array}$ & $\begin{array}{r}-54.227 \\
391\end{array}$ & $\begin{array}{r}-159.048 \\
1131\end{array}$ & & $\begin{array}{r}-88.224 \\
425\end{array}$ & $\begin{array}{r}-41.317 \\
321\end{array}$ \\
\hline
\end{tabular}

Notes: $* * *, * * *$ denote statistical significance at the $10 \%, 5 \%$, and $1 \%$ levels, respectively.

The prefecture dummies (47) and the occupation dummies (12) are added to the set of explanatory variables.

The estimated coefficients of those dummies are not reported in the table.

Table A4: Binary probit regression of severe obesity with prefecture and occupation dummies

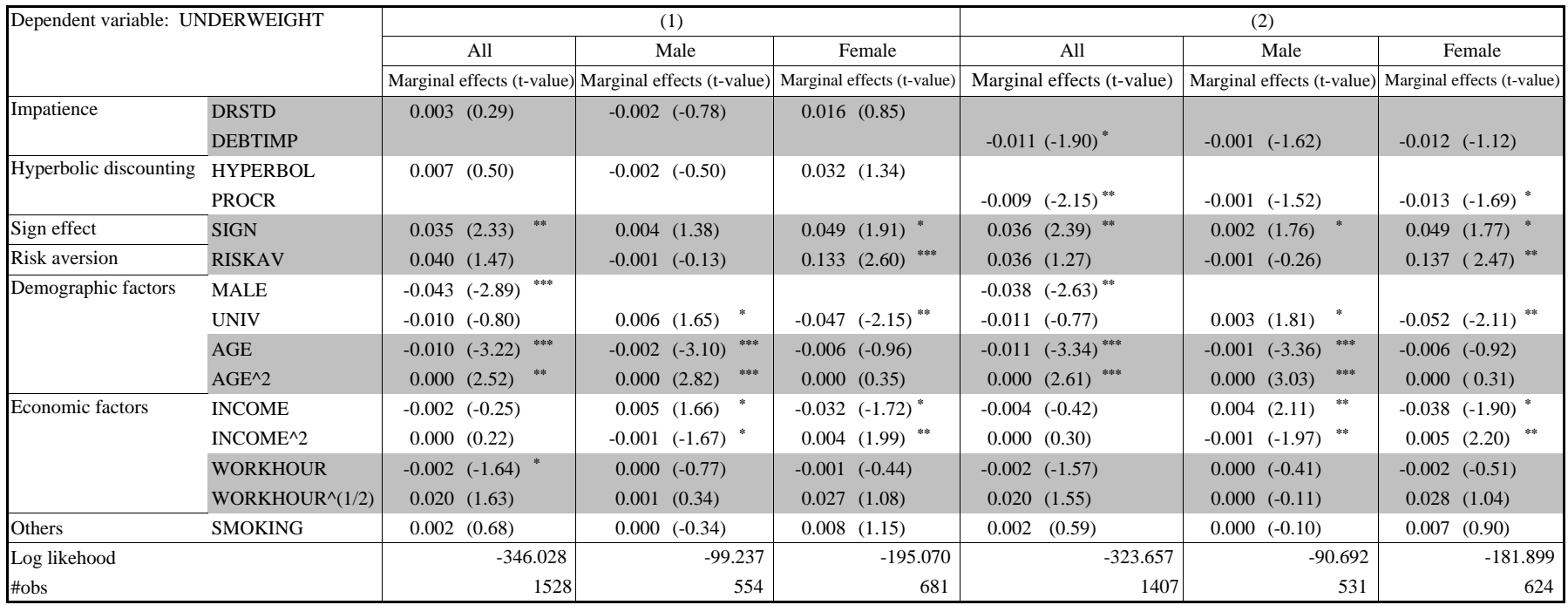

Notes: *,**, *** denote statistical significance at the $10 \%, 5 \%$, and $1 \%$ levels, respectively.

The prefecture dummies (47) and the occupation dummies (12) are added to the set of explanatory variables.

The estimated coefficients of those dummies are not reported in the table. 
Table A5: Multivariate probit estimation of the prob. of obesity, severe obesity, and underweight

\begin{tabular}{|c|c|c|c|c|c|c|c|}
\hline \multirow{2}{*}{\multicolumn{2}{|c|}{$\begin{array}{l}\text { Dependent variables: } \\
\text { OBESITY, SEVERE OBESITY, } \\
\text { UNDERWEIGHT }\end{array}$}} & \multicolumn{3}{|c|}{ Model (1) } & \multicolumn{3}{|c|}{ Model (2) } \\
\hline & & $\begin{array}{c}\text { Obesity } \\
\text { Coef. (t-value) }\end{array}$ & $\begin{array}{l}\text { Severe Obesity } \\
\text { Coef. (t-value) }\end{array}$ & $\begin{array}{l}\text { Underweight } \\
\text { Coef. (t-value) }\end{array}$ & $\begin{array}{c}\text { Obesity } \\
\text { Coef. (t-value) }\end{array}$ & $\begin{array}{c}\text { Severe Obesity } \\
\text { Coef. (t-value) }\end{array}$ & $\begin{array}{l}\text { Underweight } \\
\text { Coef. (t-value) }\end{array}$ \\
\hline Impatience & $\begin{array}{l}\text { DRSTD } \\
\text { DEBTIMP }\end{array}$ & $0.197 \quad(3.03)$ & $-0.016(-0.14)$ & $0.068(0.75)$ & $0.089(2.62)^{* * * *}$ & $0.116(1.94)$ & $-0.084(-1.60)$ \\
\hline $\begin{array}{l}\text { Hyperbolic } \\
\text { discounting }\end{array}$ & $\begin{array}{l}\text { HYPERBOL } \\
\text { PROCR }\end{array}$ & $0.129(1.43)$ & $0.000(0.00)$ & $0.065(0.50)$ & $0.090(3.20)^{* * *}$ & $0.123(2.29)^{* *}$ & $-0.092(-2.43)^{* * *}$ \\
\hline $\begin{array}{l}\text { Sign effect } \\
\text { Risk aversion }\end{array}$ & $\begin{array}{l}\text { SIGN } \\
\text { RISKAV }\end{array}$ & $-0.032(-0.29)$ & $\begin{array}{ll}-0.356 & (-2.12) \\
-0.559 & (-1.87)^{* *}\end{array}$ & $\begin{array}{ll}0.442(2.33) \\
0.318(1.26)\end{array}$ & $\begin{array}{ll}-0.020 & (-0.18) \\
-0.256 & (-1.48)\end{array}$ & $\begin{array}{ll}-0.264 & (-1.50) \\
-0.679 & (-2.24)\end{array}$ *** & $\begin{array}{ll}0.481 \quad(2.50) \\
0.325(1.27)\end{array}$ \\
\hline \multirow[t]{2}{*}{$\begin{array}{l}\text { Demographic } \\
\text { factors }\end{array}$} & $\begin{array}{l}\text { MALE } \\
\text { UNIV }\end{array}$ & $\begin{aligned} 0.335 & (3.82)^{* * *} \\
-0.190 & (-2.11)\end{aligned}$ & $\begin{aligned} 0.202 & (1.30) \\
-0.113 & (-0.70)\end{aligned}$ & $\begin{array}{l}-0.252(-2.03))^{* *} \\
-0.094(-0.74)\end{array}$ & $\begin{aligned} 0.276 & (3.11) \\
-0.189 & (-2.08)^{* * *}\end{aligned}{ }^{* *}$ & $\begin{aligned} & (1.48) \\
-0.078 & (-0.47)\end{aligned}$ & $\begin{array}{ll}-0.251 \quad\left(-2.00^{* * *}\right. \\
-0.126(-0.97)\end{array}$ \\
\hline & $\begin{array}{l}\mathrm{AGE} \\
\mathrm{AGE}^{\wedge} 2\end{array}$ & $\left.\begin{array}{rr}0.070(3.14) & * * \\
-0.001 & (-2.70)\end{array}\right)^{* * * *}$ & $\begin{array}{ll}0.035 & (0.89) \\
0.000 & (-0.79)\end{array}$ & $\begin{aligned}-0.104 & (-3.83)^{* * *} \\
0.001 & (3.04)^{* * *}\end{aligned}$ & $\begin{array}{rr}0.075 & (3.33) \\
-0.001 & (-2.82)^{* * * *}\end{array}$ & $\begin{array}{ll}0.017 & (0.42) \\
0.000 & (-0.21)\end{array}$ & $\begin{aligned}-0.109 & (-3.98)^{* * *} \\
0.001 & (3.21)^{* * *}\end{aligned}$ \\
\hline \multirow[t]{2}{*}{$\begin{array}{l}\text { Economic } \\
\text { factors }\end{array}$} & $\begin{array}{l}\text { INCOME } \\
\text { INCOME`2 }^{2}\end{array}$ & $\begin{array}{rrr}-0.108 & (-2.01) & * * \\
0.016 & (2.71) & * * *\end{array}$ & $\begin{aligned}-0.079 & (-0.93) \\
0.011 & (1.30)\end{aligned}$ & $\begin{aligned}-0.046 & (-0.60) \\
0.002 & (0.26)\end{aligned}$ & $\begin{aligned}-0.123 & (-2.26)^{* *} \\
0.018 & (2.97)\end{aligned}{ }^{* * * *}$ & $\left.{ }_{-0.144}(-1.65)\right)^{*}$ & $\begin{array}{rr}-0.050 & (-0.62) \\
0.003 & (0.28)\end{array}$ \\
\hline & $\begin{array}{l}\text { WORKHOUR } \\
\text { WORKHOUR^(1/2) }\end{array}$ & $\begin{aligned} 0.014 & (2.16) \\
-0.095 & (-2.00)^{* * *}\end{aligned}$ & $\begin{aligned} 0.005 & (0.40) \\
-0.039 & (-0.45)\end{aligned}$ & $\begin{array}{rr}-0.019 & (-1.94)^{* *} \\
0.134 & (1.94)\end{array}{ }^{* *}$ & $\begin{aligned} 0.013 & (1.95) \\
-0.088 & (-1.84)^{*}\end{aligned}$ * & $\begin{array}{rr}0.002 & (0.17) \\
-0.015 & (-0.18)\end{array}$ & $\begin{aligned}-0.017 & (-1.69) \\
0.125 & (1.76)\end{aligned}$ \\
\hline Others & $\begin{array}{l}\text { SMOKING } \\
\text { Constant }\end{array}$ & $\begin{array}{ll}-0.012 & (-0.56) \\
-2.459 & (-4.74)^{* * * *}\end{array}$ & $\begin{array}{l}-0.035(-0.88) \\
-2.110(-2.31)\end{array}$ & $\begin{array}{ll}0.021 & (0.66) \\
0.733 & (1.20)\end{array}$ & $\begin{array}{ll}-0.011 \quad(-0.51) \\
-2.769 \quad(-5.18\end{array}{ }^{* * * *}$ & $\begin{array}{ll}-0.058 & (-1.42) \\
-2.197 & (-2.34)\end{array}{ }^{* *}$ & $\begin{array}{l}0.011(0.34) \\
1.160 \quad(1.84)\end{array}{ }^{*}$ \\
\hline \multicolumn{2}{|c|}{ Correlation matrix of error terms } & 1 & $\begin{array}{l}0.759(15.61)^{* * *} \\
1\end{array}$ & $\begin{array}{rr}-0.422 & (-6.04)^{* * *} \\
-0.252 & (-8.66)^{* * *} \\
1 & \end{array}$ & 1 & $0.748(14.63)^{* * *}$ & \begin{tabular}{rr|}
-0.406 & $(-6.10)^{* * * *}$ \\
-0.320 & $(-3.64)^{* * * *}$ \\
1 &
\end{tabular} \\
\hline \multicolumn{2}{|c|}{ Loglikelihood ratio test: } & \multicolumn{3}{|c|}{$\begin{array}{l}\mathrm{H}_{0} \text { : all error term correlations }=0, \\
\chi^{2}(3)=144.499 \text { Prob }>\chi^{2}=0.000\end{array}$} & \multicolumn{3}{|c|}{$\begin{array}{l}\mathrm{H}_{0}: \text { all error term correlations }=0 \\
\chi^{2}(3)=137.479 \text { Prob }>\chi^{2}=0.000\end{array}$} \\
\hline $\begin{array}{l}\text { Log likelihoo } \\
\text { \#obs }\end{array}$ & & & & $\begin{array}{r}-1386.588 \\
1658\end{array}$ & & & $\begin{array}{r}-1361.592 \\
1629\end{array}$ \\
\hline
\end{tabular}

Notes: $*, * *, * *$ denote statistical significance at the $10 \%, 5 \%$, and $1 \%$ levels, respectively.

The estimation is conducted by using the "mvprobit" program in the software STATA. 
Table A6: OLS regression of uncorrected BMI

\begin{tabular}{|c|c|c|c|c|c|c|c|c|c|c|}
\hline & \multicolumn{3}{|c|}{ Model (1) } & \multicolumn{6}{|c|}{ Model (2) } \\
\hline \multirow{2}{*}{\multicolumn{2}{|c|}{ Dependent variable: BMI }} & \multirow{2}{*}{$\begin{array}{c}\text { All } \\
\text { Coef. (t-value) }\end{array}$} & \multirow{2}{*}{$\begin{array}{c}\text { Male } \\
\text { Coef. (t-value) }\end{array}$} & \multirow{2}{*}{$\begin{array}{c}\text { Female } \\
\text { Coef. (t-value) }\end{array}$} & \multicolumn{3}{|c|}{ All } & Male & \multicolumn{2}{|l|}{ Female } \\
\hline & & & & & \multicolumn{3}{|c|}{ Coef. (t-value) } & Coef. (t-value) & \multicolumn{2}{|l|}{ Coef. (t-value) } \\
\hline Impatience & $\begin{array}{l}\text { DRSTD } \\
\text { DEBTIMP }\end{array}$ & $0.273(2.025)$ & $0.276(1.421)$ & $0.256 \quad(1.363)$ & 0.24 & $(3.400)$ & $* * *$ & $0.167(1.574)$ & 0.314 (3.199) & ${ }^{* * *}$ \\
\hline $\begin{array}{l}\text { Hyperbolic } \\
\text { discounting }\end{array}$ & $\begin{array}{l}\text { HYPERBOL } \\
\text { PROCR }\end{array}$ & $0.105(0.565)$ & $0.177 \quad(0.647)$ & $0.014(0.056)$ & 0.21 & (3.796) & $* * *$ & $0.179(2.08){ }^{* *}$ & $0.240(3.178)$ & $* * *$ \\
\hline Sign effect & SIGN & $-0.550(-2.400)$ ** & $-0.300(-0.863)$ & $-0.723(-2.400)^{* *}$ & -0.49 & $(-2.159)$ & & $-0.165(-0.491)$ & $-0.743(-2.447)$ & \\
\hline Risk aversion & RISKAV & $-0.659(-1.805)^{*}$ & $-0.972(-1.872)$ * & $-0.465(-0.902)$ & -0.81 & $(-2.243)$ & $* *$ & $-0.992(-1.933)$ * & $-0.725(-1.412)$ & \\
\hline Demographic factors & $\begin{array}{l}\text { MALE } \\
\text { UNIV }\end{array}$ & $\begin{aligned} 1.301 & (7.191) \\
-0.118 & (-0.648)\end{aligned}$ & $-0.256(-1.081)$ & $0.059(0.203)$ & $\begin{array}{r}1.21 \\
-0.13\end{array}$ & $\begin{array}{l}(6.622) \\
(-0.748)\end{array}$ & ${ }^{* * *}$ & $-0.247 \quad(-1.047)$ & $-0.046 \quad(-0.155)$ & \\
\hline & $\begin{array}{l}\mathrm{AGE} \\
\mathrm{AGE} \wedge 2\end{array}$ & $\begin{aligned} 0.238 & (5.470) \\
-0.002 & (-4.643)^{* * * *}\end{aligned}$ & $\begin{aligned} 0.230 & (3.508) \\
-0.002 & (-3.244)\end{aligned}$ & $\begin{aligned} 0.235 & (3.865)^{* * * *} \\
-0.002 & (-2.922)^{* * *}\end{aligned}$ & $\begin{array}{r}0.238 \\
-0.00\end{array}$ & $\begin{array}{l}(5.438) \\
(-4.542)\end{array}$ & & $\begin{aligned} 0.226 & (3.468) \\
-0.002 & (-3.180)^{* * * *}\end{aligned}$ & $\begin{aligned} 0.242 & (3.971) \\
-0.002 & (-2.965)\end{aligned}$ & \\
\hline Economic factors & $\begin{array}{l}\text { INCOME } \\
\text { INCOME^2 }\end{array}$ & $\begin{aligned}-0.257 & (-2.297)^{* *} \\
0.038 & (3.000)\end{aligned}$ & $\begin{aligned}-0.130 & (-0.876) \\
0.026 & (1.727)\end{aligned}$ * & $\begin{aligned}-0.518 & (-2.599)^{* * *} \\
0.067 & (2.533)^{* *}\end{aligned}$ & $\begin{array}{r}-0.27 \\
0.03\end{array}$ & $\begin{array}{l}(-2.352) \\
(2.804)\end{array}$ & ${ }^{* *}$ & $\begin{aligned}-0.105 & (-0.682) \\
0.021 & (1.336)\end{aligned}$ & $\begin{aligned}-0.604 & (-3.031) \\
0.076 & (2.861)\end{aligned}$ & $\begin{array}{l}* * * \\
* * *\end{array}$ \\
\hline & $\begin{array}{l}\text { WORKHOUR } \\
\text { WORKHOUR } \wedge(1 / 2\end{array}$ & $\begin{array}{r}0.030(2.215) \\
-0.202(-2.044)^{* *}\end{array}$ & $\begin{aligned} 0.008 & (0.426) \\
-0.032 & (-0.207)\end{aligned}$ & $\begin{array}{r}0.037(1.734)^{*} \\
-0.264(-1.847)^{*}\end{array}$ & $\begin{array}{r}0.02 \\
-0.18\end{array}$ & $\begin{array}{l}(1.950) \\
(-1.849)\end{array}$ & & $\begin{array}{ll}0.004 & (-0.213) \\
0.056 & (0.357)\end{array}$ & $\begin{aligned} 0.048 & (2.197) \\
-0.337 & (-2.310)\end{aligned}$ & \\
\hline Others & $\begin{array}{l}\text { SMOKING } \\
\text { Constant }\end{array}$ & $\begin{array}{l}-0.055(-1.197) \\
17.019(17.013)^{* * *}\end{array}$ & $\begin{array}{r}-0.046(-0.817) \\
18.705(12.965)^{* * *}\end{array}$ & $\begin{aligned}-0.097 & (-1.161) \\
17.103 & (12.145\end{aligned}$ & $\begin{array}{l}-0.068 \\
16.458\end{array}$ & $\begin{array}{l}(-1.476) \\
(16.180)\end{array}$ & & $\begin{array}{l}-0.041(-0.738) \\
18.063(12.337)^{* * * *}\end{array}$ & $\begin{array}{rr}-0.149 & (-1.759) \\
16.537 & (11.651)\end{array}$ & \\
\hline \begin{tabular}{|l} 
Adj. $R^{\wedge} 2$ \\
$\#$ obs
\end{tabular} & & \begin{tabular}{c|}
0.094 \\
1658 \\
\end{tabular} & $\begin{array}{r}0.021 \\
818 \\
\end{array}$ & $\begin{array}{r}0.079 \\
840 \\
\end{array}$ & & & $\begin{array}{r}0.102 \\
1629\end{array}$ & $\begin{array}{r}0.023 \\
812\end{array}$ & & $\begin{array}{r}0.110 \\
817\end{array}$ \\
\hline
\end{tabular}

Notes: The uncorrected BMI data from JHS05 are used. *, **, *** denote statistical significance at the $10 \%, 5 \%$, and $1 \%$ levels, respectively.

Table A7: Binary probit regression of obesity by the uncorrected data

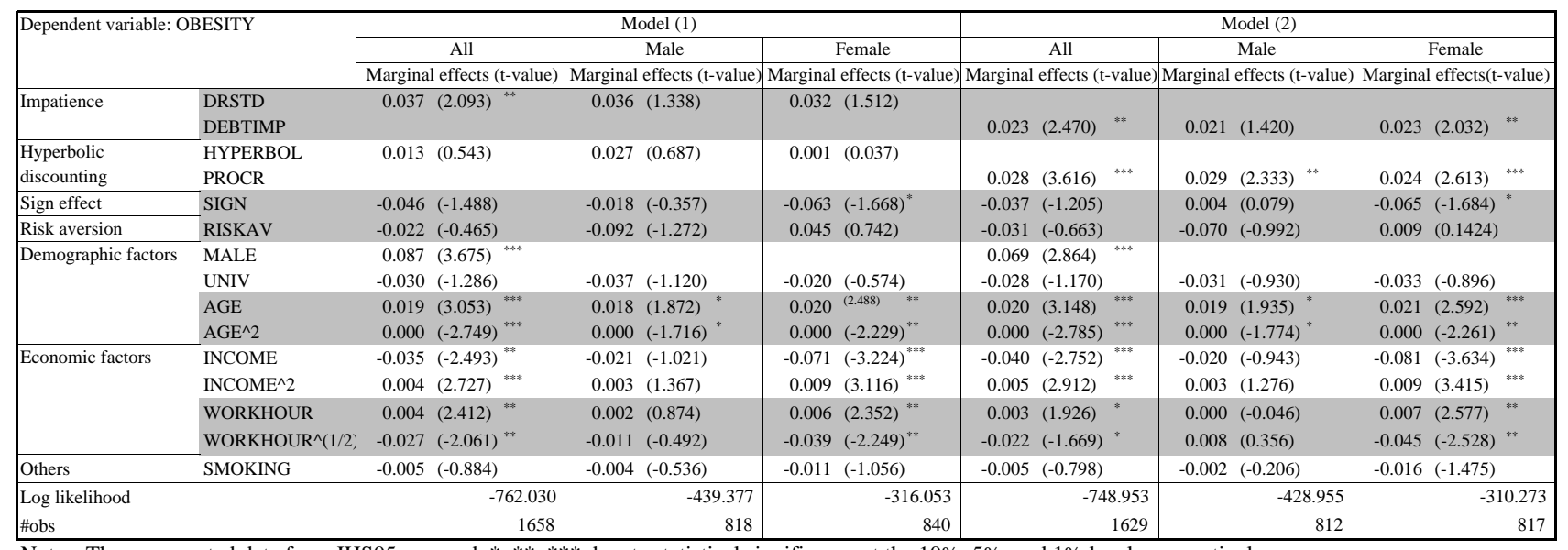

Notes: The uncorrected data from JHS05 are used. *, **, *** denote statistical significance at the $10 \%, 5 \%$, and $1 \%$ levels, respectively.

Table A8: Binary probit regression of severe obesity by the uncorrected data

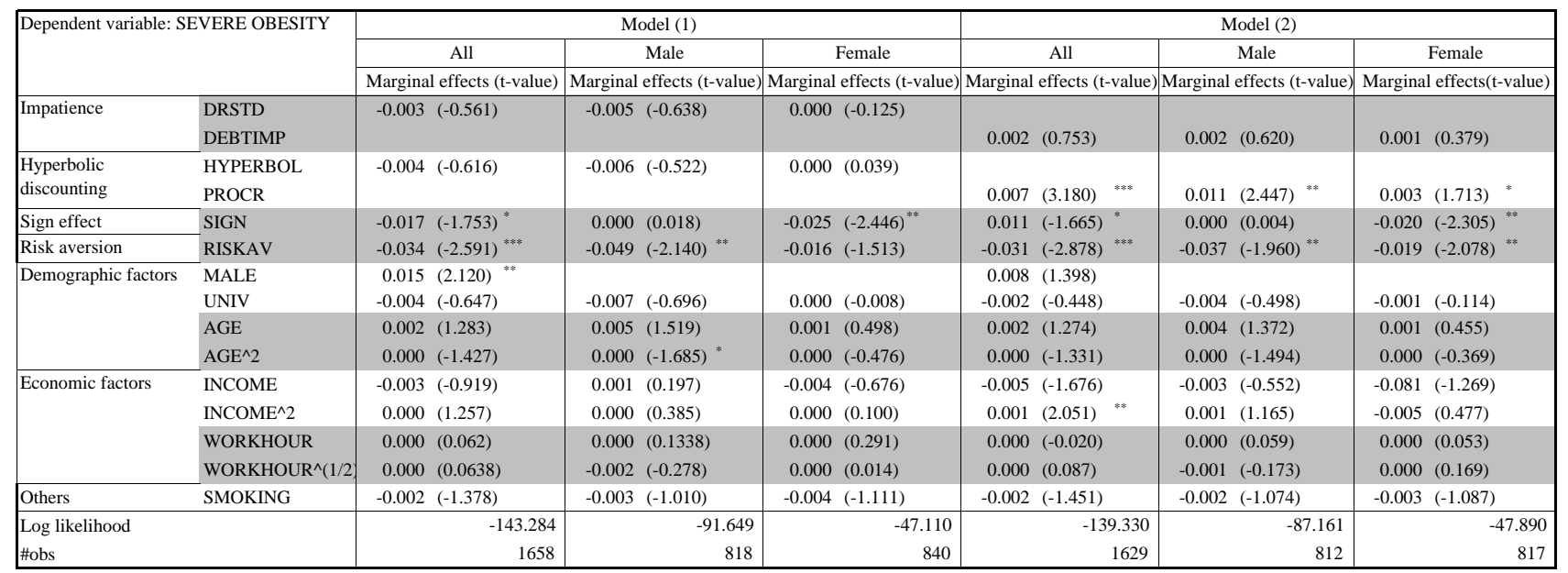

Notes: The uncorrected data from JHS05 are used. *,**,*** denote statistical significance at the $10 \%, 5 \%$, and $1 \%$ levels, respectively. 
Figure 1: BMI distribution: NSHN04, JHS05, corrected data
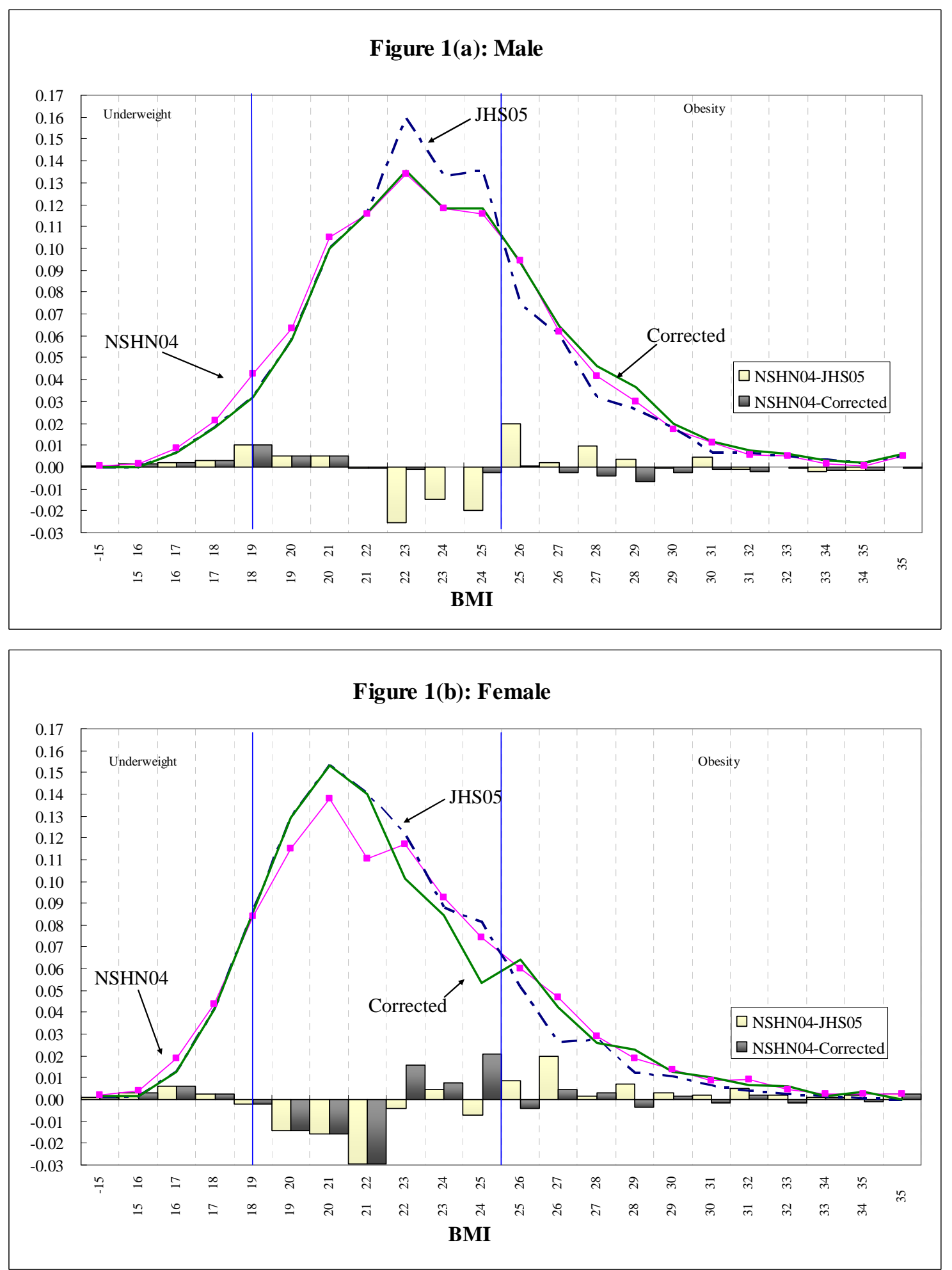

Note: NSHN04, JHS05, and corrected data represent the National Survey of Health and Nutrition 2004, the Japan Household Survey on Consumer Preferences and Satisfaction 2005, and the corrected data of JHS05, respectively. 
Figure 2(a) Income and BMI: Female (model (1))

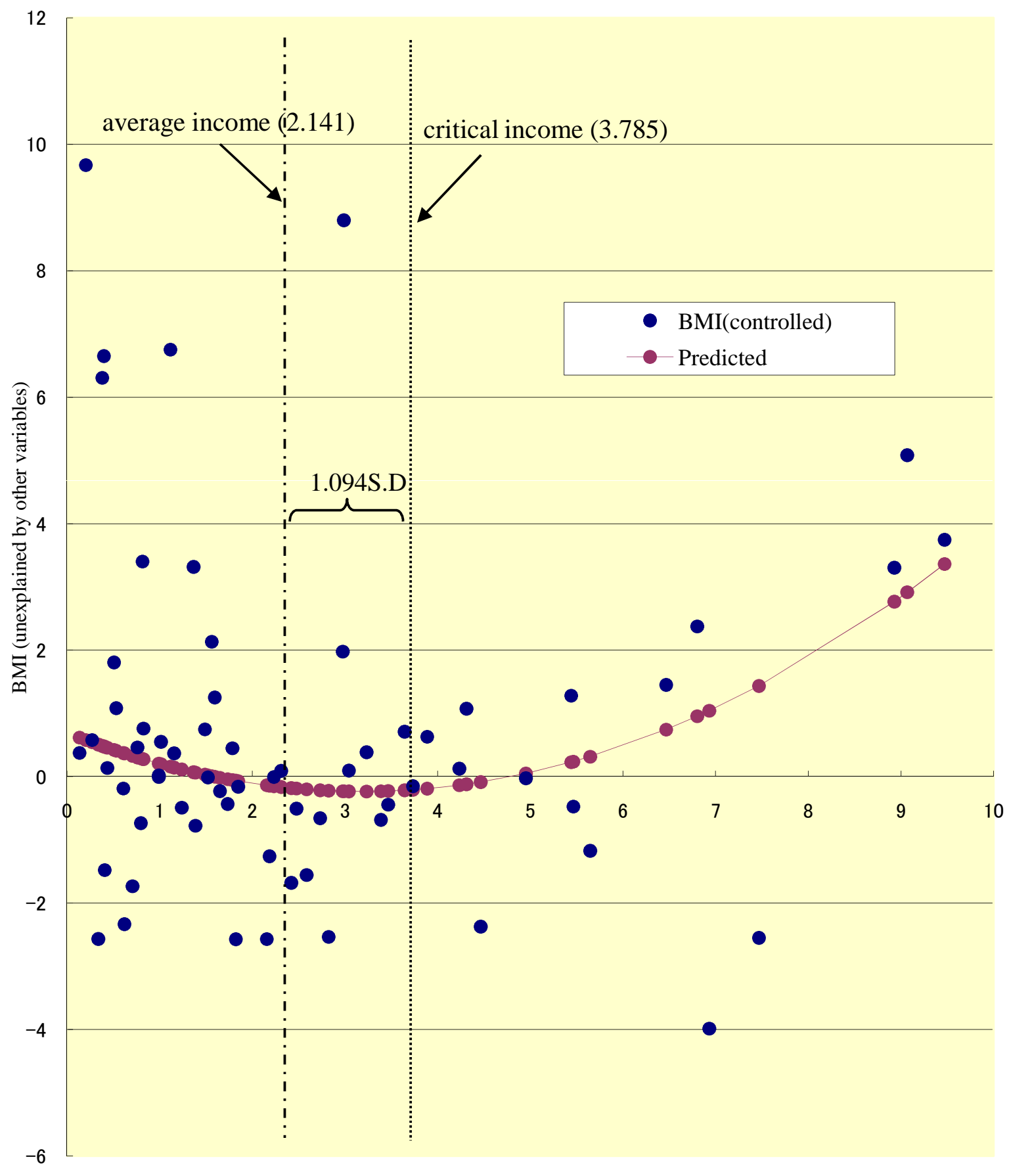

Per capita household income (million JPY) 


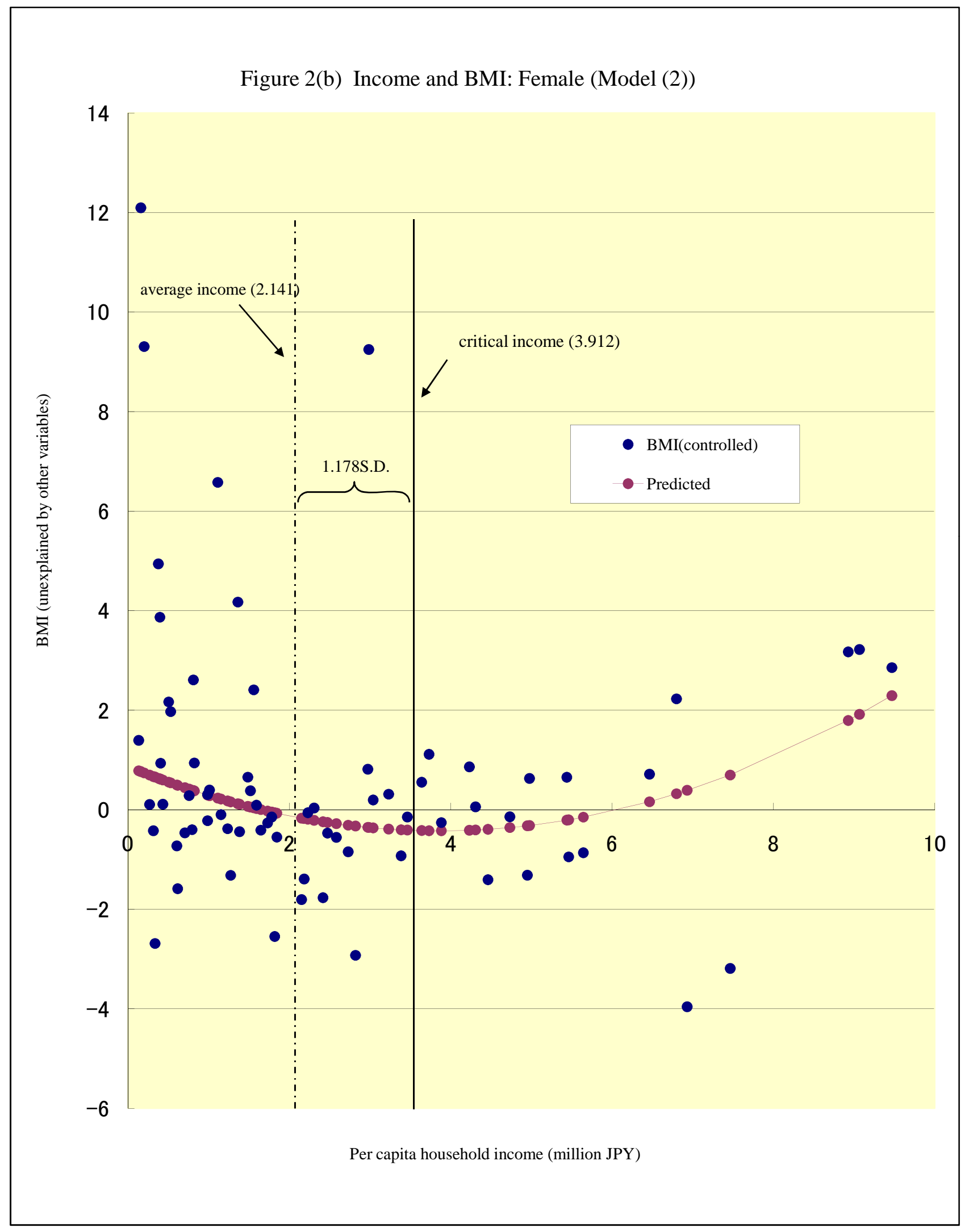


Figure 3: Females' Income Elasticities of BMI in Income Quintiles

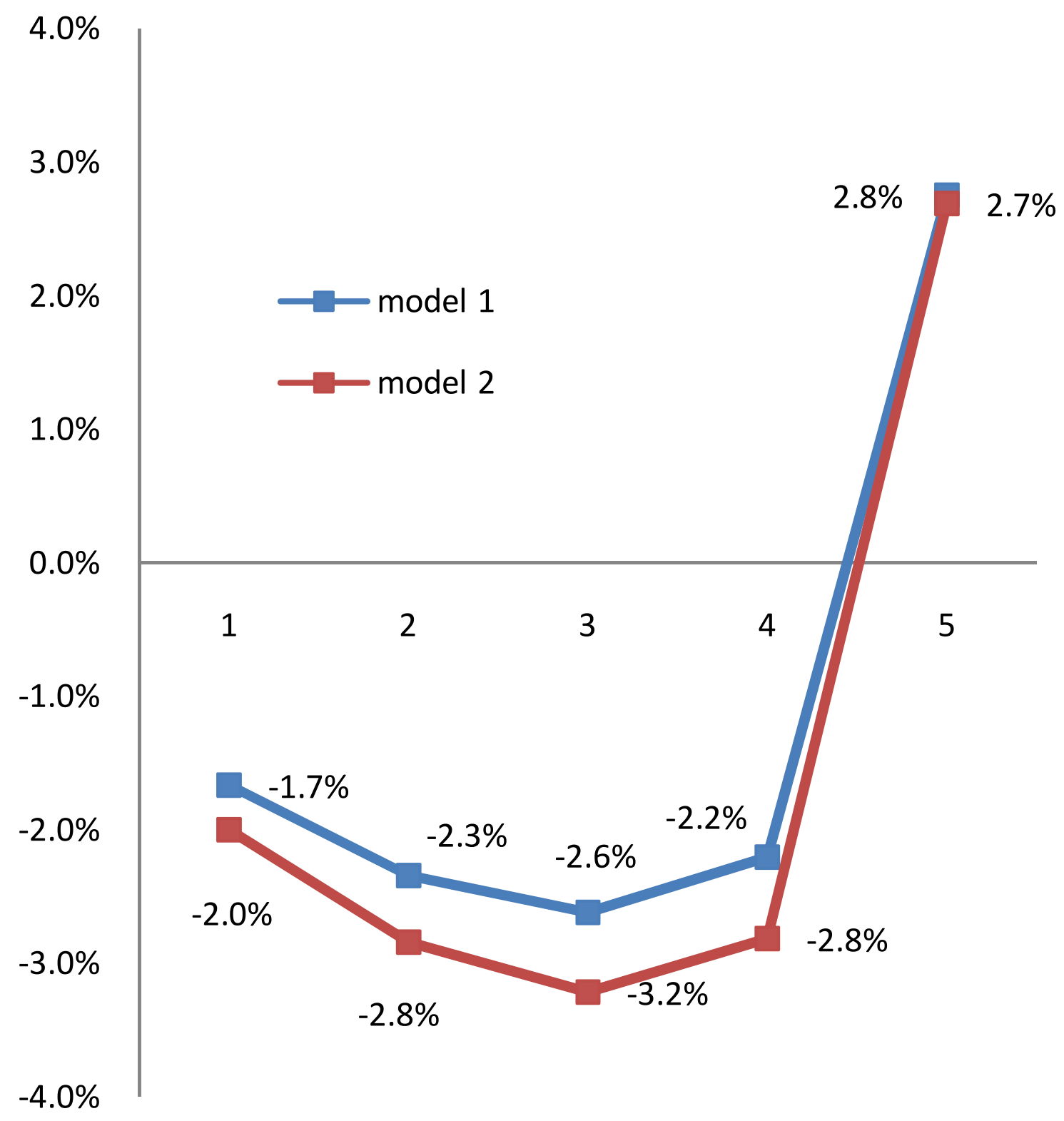


Figure 4: Females' Working Hour Elasticities of BMI

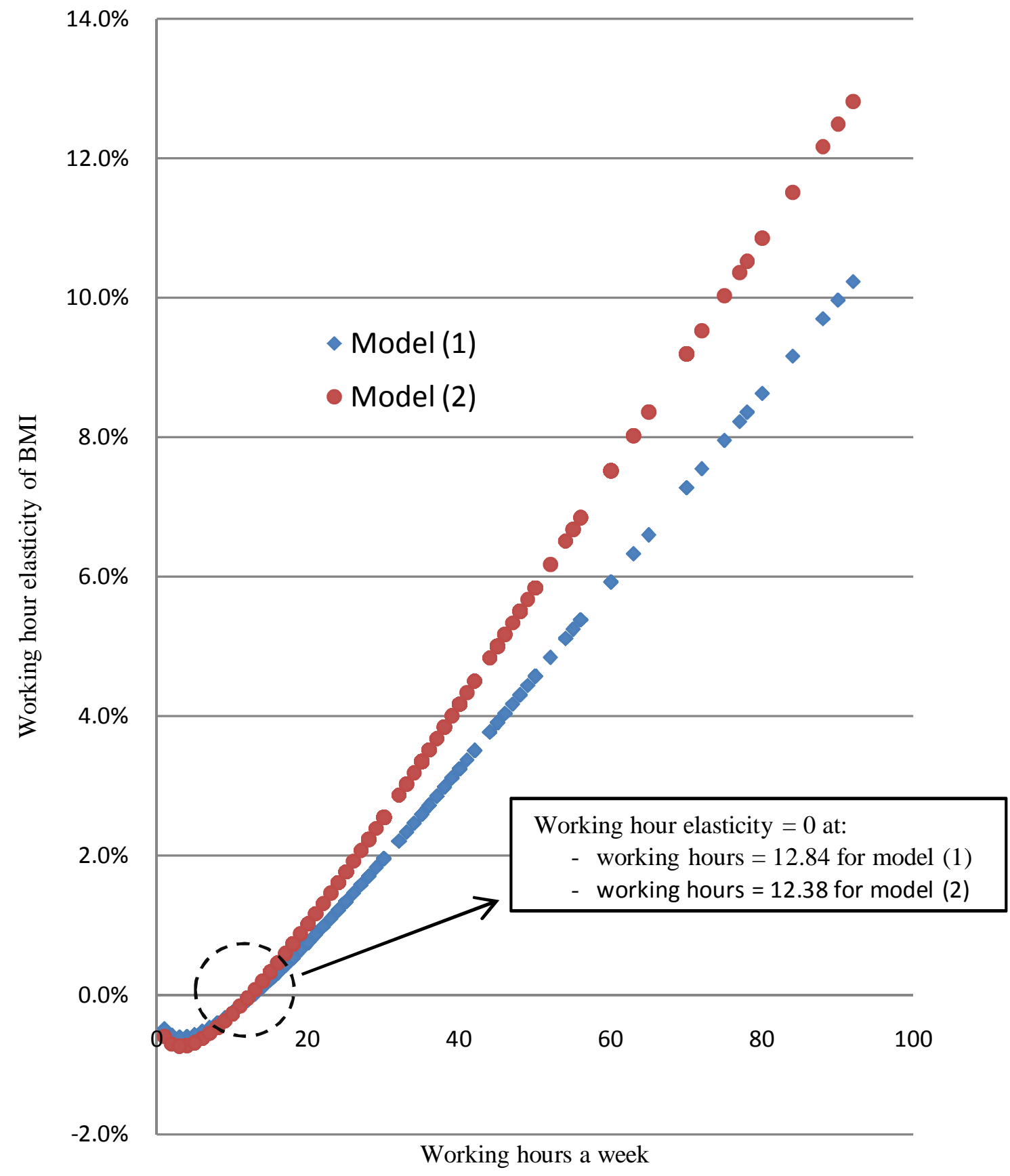

